\title{
Review
}

\author{
Pamela Pinzani, Valeria D’Argenio, Marzia Del Re, Cristina Pellegrini, Federico Cucchiara, \\ Francesca Salvianti and Silvia Galbiati*
}

\section{Updates on liquid biopsy: current trends and future perspectives for clinical application in solid tumors}

https://doi.org/10.1515/cclm-2020-1685

Received November 9, 2020; accepted January 20, 2021;

published online February 5, 2021

\begin{abstract}
Despite advances in screening and therapeutics cancer continues to be one of the major causes of morbidity and mortality worldwide. The molecular profile of tumor is routinely assessed by surgical or bioptic samples, however, genotyping of tissue has inherent limitations: it represents a single snapshot in time and it is subjected to spatial selection bias owing to tumor heterogeneity. Liquid biopsy has emerged as a novel, non-invasive opportunity of detecting and monitoring cancer in several body fluids instead of tumor tissue. Circulating tumor cells (CTCs), circulating tumor DNA (ctDNA), RNA (mRNA and microRNA), microvesicles, including exosomes and tumor "educated platelets" were recently identified as a source of genomic information in cancer patients which could reflect all subclones present in primary and metastatic lesions allowing sequential monitoring of disease evolution. In this review, we summarize the currently available information concerning liquid biopsy in breast cancer, colon cancer, lung cancer and melanoma. These promising issues still need to be standardized and harmonized across
\end{abstract}

\footnotetext{
*Corresponding author: Silvia Galbiati, PhD, Diabetes Research Institute, IRCCS Ospedale San Raffaele, Via Olgettina 60, 20132 Milan, Italy, Phone: +39 02 26434779, Fax: +3902 26434351,

E-mail: galbiati.silvia@hsr.it

Pamela Pinzani and Francesca Salvianti, Department of Experimental and Clinical Biomedical Sciences "Mario Serio", University of Florence, Florence, Italy

Valeria D’Argenio, Department of Human Sciences and Quality of Life Promotion, San Raffaele Open University, Rome, Italy; and

CEINGE-Biotecnologie Avanzate, Naples, Italy

Marzia Del Re and Federico Cucchiara, Clinical Pharmacology and Pharmacogenetics Unit, Department of Clinical and Experimental Medicine, University of Pisa, Pisa, Italy. https://orcid.org/00000002-0946-750X (F. Cucchiara)

Cristina Pellegrini, Department of Biotechnological and Applied Clinical Sciences, University of L'Aquila, L’Aquila, Italy
}

laboratories, before fully adopting liquid biopsy approaches into clinical practice.

Keywords: cancer biomarkers; circulating cell-free DNA and RNA; circulating tumor cells; circulating tumor DNA; exosomes; liquid biopsy.

\section{Introduction}

Cancer is a spatial and temporal dynamic disease. In this scenario, the recognition of mechanisms responsible for tumor evolution remains a challenging task. Recently, there has been a notable increase in knowledge of cancer molecular bases due to the development of highly sensitive techniques leading to precision medicine. The main objective of precision oncology is to provide the most accurate and effective treatment strategy based on the genetic profile of cancer and the individual themselves [1]. One of the prime challenges for the clinical implementation of precision oncology is to detect molecular biomarkers that might enable estimation of the prognosis, predict sensitivity or resistance to a specific therapy and guide the selection of treatment through the characterization of somatic alterations involved in tumor progression [2].

Tissue biopsy is still considered the "gold standard" for diagnosis and treatment choice in cancer patients [3]. However, it is associated with inherent limitations that render tissue biopsy an unfeasible option for long term monitoring, lacking information regarding spatial and temporal heterogeneity of the tumor $[4,5]$. Indeed, the genetic landscape of the tumor and metastases dynamically changes due to the selective pressure of therapies promoting the growth of different subclones [4].

Moreover, tissue biopsy cannot be performed when clinical conditions have worsened or due to limited accessibility of tumor tissue and demands high total costs due to the complexity of the medical procedure, needing dedicated personnel, a medical surgery room available and longer recovery time $[6,7]$. 
Liquid biopsy has been recently gaining attention worldwide as a complementary tool to tissue biopsy, being a minimally invasive diagnostic tool able to assess the genetic landscape of solid tumors (Figure 1). The new field of oncology research has focused on cancerderived primary tumor and metastatic sites components that circulate in the bloodstream, including circulating tumor cells (CTCs) and stromal cells of the tumor microenvironment.

Moreover, cancer cells release circulating cell-free DNA (cfDNA) fragments, designated as circulating tumor DNA (ctDNA), RNA (mRNA and microRNA), extracellular vesicles (EV), including exosomes which are membrane-encapsulated subcellular structures containing proteins and nucleic acids, actively released by the tumor cells [5].
In Table 1 the current technologies available to analyze CTCs, cfDNA, RNA (mRNA and microRNA) and exosomes are summarized.

In addition, tumor-educated platelets (TEPs) were recently identified as a source of genomic and proteomic information in cancer patients [8].

Liquid biopsy is obtained by a routine blood draw and requires a small amount of blood, usually 6-10 mL [9]; it demands a short time and low costs for sample taking and helps understanding the spatial and temporal heterogeneity of cancer, allowing a real-time monitoring for treatment responses and resistance by repeated analysis. On the contrary, the main disadvantage is the lack of standardization of the methodologies $[10,11]$ and an often insufficient technical and clinical validation for a routine clinical implementation [12]. Moreover, in some cancer types such

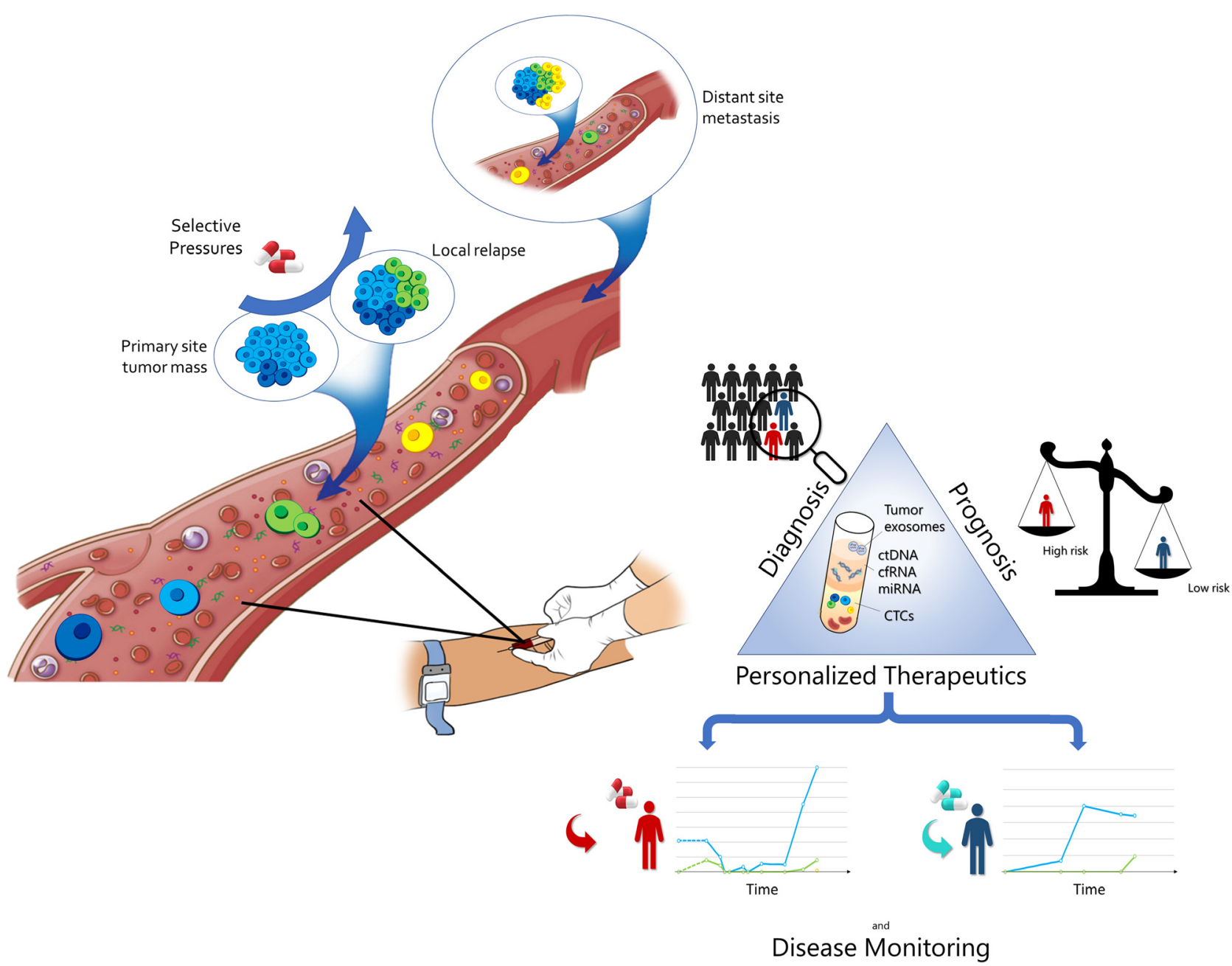

Figure 1: Clinical applications of liquid biopsy in tumor management.

CTCs, circulating tumor cells; ctDNA, circulating tumor DNA; cfRNA, circulating free RNA. 
Table 1: Current technologies available to isolate and analyze CTCs, cfDNA, RNA (mRNA and microRNA) and exosomes.

\begin{tabular}{|c|c|c|c|c|}
\hline CTCs & & & $\begin{array}{l}\text { cfDNA, cfRNA, and } \\
\text { miRNA }\end{array}$ & Exosomes \\
\hline $\begin{array}{l}\text { Enrichment } \\
-\quad \text { Physical properties } \\
\text { (size, density) } \\
\text { - Biological characteristics } \\
\quad \text { (marker expression) }\end{array}$ & $\begin{array}{ll}\text { Isolation } \\
-\quad \text { Mirofluidics dielectroph } \\
-\quad \text { Micromanipulation } \\
-\quad \text { Flow cytometry } \\
\text { - } & \text { Laser microdissection }\end{array}$ & oresis & $\begin{array}{l}\text { Isolation } \\
-\quad \text { Manual protocols } \\
-\quad \text { Automated } \\
\quad \text { procedures }\end{array}$ & $\begin{array}{l}\text { Isolation } \\
-\quad \text { Ultracentrifugation } \\
-\quad \text { Size exclusion } \\
\text { chromatography } \\
\text { - } \quad \text { Membrane affinity } \\
\text { purification } \\
\text { - Immunocapture } \\
-\quad \text { Chemical } \\
\text { - } \quad \text { precipitation } \\
\text { Polymer precipitation }\end{array}$ \\
\hline $\begin{array}{l}\text { Bulk analysis } \\
\text { CTC enumeration } \\
\text { Molecular profiling: } \\
-\quad \text { Genomic analysis } \\
-\quad \text { Transcritpomic analysis } \\
-\quad \text { Epigenetic analysis } \\
-\quad \text { Proteomic analysis }\end{array}$ & $\begin{array}{l}\frac{\text { Pure CTCs }}{\text { Molecular profiling: }} \\
-\quad \text { Genomic analysis } \\
-\quad \text { Epigenetic analysis } \\
-\quad \text { Proteomic analysis } \\
-\quad \text { Metabolomic analysis }\end{array}$ & $\begin{array}{l}\text { Single CTCS } \\
\text { Molecular profiling: } \\
-\quad \text { Genomic analysis } \\
-\quad \text { Epigenetic } \\
\quad \text { analysis } \\
-\quad \text { Proteomic } \\
\quad \text { analysis } \\
-\quad \text { Metabolomic } \\
\quad \text { analysis }\end{array}$ & $\begin{array}{ll}\text { Molecular profiling: } \\
-\quad \text { Genomic analysis } \\
-\quad \text { Mutation analysis } \\
-\quad \text { Transcritpomic } \\
\quad \text { analysis } \\
-\quad \text { Epigenetic } \\
\quad \text { analysis } \\
-\quad \text { Methylation } \\
\text { analysis } \\
\text { - Gene expression } \\
\quad \text { (mRNA) } \\
-\quad \text { miRNA, } \\
\text { IncRNA analysis } \\
\text { - Tumor } \\
\text { heterogeneity }\end{array}$ & $\begin{array}{ll}\text { Molecular profiling: } \\
-\quad \text { Mutation analysis } \\
-\quad \text { Transcritpomic } \\
\quad \text { analysis } \\
-\quad \text { Gene } \\
& \text { expression (mRNA) } \\
- & \text { miRNA, IncRNA analysis } \\
- & \text { Proteomic analysis } \\
- & \text { Metabolomic analysis }\end{array}$ \\
\hline $\begin{array}{ll}\text { Methodologies: } \\
- & \text { Immunocytochemistry (IHC) } \\
& \text { analysis } \\
- & \text { Immuno fluorescent staining } \\
- & \text { Fluorescence in situ } \\
& \text { hybridization(FISH) } \\
- & \text { qPCR } \\
- & \text { ddPCR } \\
- & \text { NGS }\end{array}$ & $\begin{array}{l}\text { Methodologies: } \\
\text { WGA prior to genomic anal- } \\
\text { ysis } \\
\text { WTA prior to transcritpomic } \\
\text { analysis } \\
-\quad \text { FISH } \\
-\quad \text { Comparative genomic } \\
\quad \text { hybridization (CGH) } \\
\quad \text { analysis } \\
-\quad \text { Sanger sequencing } \\
-\quad \text { qPCR } \\
-\quad \text { ddPCR } \\
-\quad \text { NGS } \\
-\quad \text { Mass spectrometry }\end{array}$ & $\begin{array}{l}\text { Methodologies: } \\
\text { WGA prior to genomic } \\
\text { analysis } \\
\text { WTA prior to tran- } \\
\text { scritpomic analysis } \\
-\quad \text { FISH } \\
-\quad \text { CGH analysis } \\
-\quad \text { Sanger } \\
-\quad \text { sequencing } \\
-\quad \text { qPCR } \\
-\quad \text { ddPCR } \\
-\quad \text { NGS } \\
-\quad \text { Mass } \\
\quad \text { spectrometry }\end{array}$ & $\begin{array}{ll}\text { Methodologies: } \\
-\quad \text { PPCR } \\
-\quad \text { ddPCR } \\
-\quad \text { NGS }\end{array}$ & \begin{tabular}{ll}
\multicolumn{1}{l}{ Methodologies: } \\
$-\quad$ Exosomes \\
& enumeration \\
- & qPCR \\
- & ddPCR \\
- & NGS
\end{tabular} \\
\hline
\end{tabular}

CTCs, circulating tumor cells; ctDNA, circulating tumor DNA; cfRNA, circulating free RNA; NGS, next generation sequencing; IHC, immunocytochemistry; FISH, fluorescence in situ hybridization; CGH, comparative genomic hybridization.

as breast or lung cancer, the subtyping diagnosis can be established only by histology [13].

\section{Circulating tumor cells}

CTCs are released from solid tumors into the circulation of cancer patients at any stage of the disease [14]. The use of CTCs in clinical practice is still limited, probably due to the technical challenges in approaching CTC analysis. CTCs are rare into the circulation [15], are dynamically heterogeneous [16] and require sophisticated techniques to be detected.

Methods for CTC enrichment refer to the following criteria: recognition of CTCs on the basis of their physical properties [17] or biological characteristics, like the expression of protein markers. Among label-dependent techniques, immunomagnetic-based assays targeting the EpCAM proteins are the most commonly applied to epithelial tumors [18]. Each approach to CTC identification 
shows its advantages and drawbacks, in particular labeldependent approaches are biased by the specificity of the marker selected, while physical approaches often require a confirmation of the malignant nature of the identified cells.

The different approaches currently available have been recently summarized in Bankó et al. and Shen et al. $[19,20]$. The latest advances in CTC isolation technology are represented by microfluidic devices resorting to a biochemical or biophysical approach or a combination of the two principles [21].

CTCs can be present in aggregates, so called circulating tumor microemboli (CTM), presenting a stronger metastatic potential than single CTCs [22, 23]. The presence of CTC clusters in the circulation of cancer patients has long been observed in different cancers [24-30] and linked to a worse prognosis [23], but only recently studies revealed the molecular bases of their increased metastatic capacity [22, 23]. CTC enrichment and isolation methods not always allow the identification of CTM and often disrupt them, which led to overlook CTC clusters in studies on CTCs. At present, with the awareness that CTM represent a distinct CTC population worth investigating, the need of isolation technologies for CTC clusters is emerging and methods for CTC enrichment with the ability to isolate CTM have been recently reviewed [31] together with the development of CTM dedicated microfluidic devices [32, 33].

The clinical validity of CTCs has been demonstrated in different contexts: cancer screening, cancer prognosis, and monitoring of treatment response [34].

CTC counting in early stage cancers, although limited by the low number of detectable cells at this stage, has shown promising results leading to clinical trials in lung, the AIR Project [35], breast and ovarian cancer (trial NCT02608346 [34]).

In non-metastatic cancers, the presence of CTCs before surgery, has been demonstrated to be an independent prognostic factor for DFS (Disease-Free Survival) and OS in many cancers [36].

In metastatic disease CTC count has reached the highest level of clinical evidence for the prognostic value [34] leading to FDA approval CTC detection by CellSearch ${ }^{\circledR}$ system (Menarini Silicon Biosystems) in metastatic breast [37], colorectal [38], and prostate cancer [39].

CTC count has been investigated also as a tool to evaluate the efficacy of systemic treatments. A series of clinical trials has been performed or is ongoing mainly in metastatic breast cancer (MBC) patients, among which the STIC CTC trial showed that including CTC count in the therapy decision algorithm for HER2 negative, hormone receptor positive MBC patients might improve patients' outcome in the subgroup with a high CTC count before treatment [40]. The SWOG S0500 study was the first to hypothesize patient monitoring by CTC dynamics. A comprehensive review of concluded and ongoing trials using CTCs in breast cancer is provided by Schochter et al. [40].

Besides the CTC count, CTC molecular characterization is being investigated for its potential clinical use especially in treatment decisions. The CirCe T-DM1 study was the first clinical trial using the phenotype of CTCs as a decision criterion showing the presence of CTCs with HER2-amplification in advanced HER2-negative MBC patients, but failing to demonstrate the efficacy of the single agent T-DM1 may be in relation to the fact that HER2amplified CTCs represented only a fraction of the total CTCs detected in treated patients [41]. Both the number and phenotype of CTCs have been investigated for their utility in treatment decisions in the DETECT study program [40].

The molecular characterization of CTCs has revealed its clinical utility in castration resistant metastatic prostate cancer patients treated with abiraterone or enzalutamide where the detection of the splicing variant AR-V7 of the androgen receptor in CTCs is associated with resistance to these therapeutic agents. The prospective PROPHECY study demonstrated that detection of AR-V7 in CTCs is independently associated with shorter PFS and OS with abiraterone/enzalutamide [42].

Recent technology advancements allowed the isolation and characterization of single CTCs opening new perspectives in CTC analyses. The molecular analysis of CTCs in different types of cancers revealed intra-patient heterogeneity reflecting tumor heterogeneity, which is considered a hallmark of cancer and responsible for resistance to therapies [43].

Despite assessments on the importance of single CTC analysis to follow tumor evolution and efforts in developing techniques to reach the single cell level [44], to date only relatively few papers reporting the characterization of single CTCs from cancer patients have been published [45, 46], mainly due to the technical challenges presented by the isolation of pure single CTCs. Single CTC isolation, in fact, is a complex multi-step process involving CTC enrichment, isolation and a step of (whole) genome/transcriptome amplification prior to CTC mutational/transcriptional analysis [47, 48].

Analyses at single CTC resolution could offer a minimally invasive approach to study cancer also at the proteomic level but the detection of multiple proteins in CTCs remains challenging [43]. Metabolome analysis of single CTCs has been performed on samples from patients affected by gastrointestinal cancer [49], but overall 
metabolites are difficult to study due to their extreme dynamicity and lability [43].

Single-cell sorting still represents the most critical step of the whole procedure. Furthermore, the lack of integrated workflows impairs the implementation of single CTC analysis in clinical practice [47, 48].

Although the pre-analytical phase of CTC analysis has not been extensively studied so far, in a recent review we defined the crucial steps of the pre-analytical workflow for CTC analyses and summarized the emerging findings in the field [50].

\section{Circulating cell-free DNA and tumor DNA}

The presence of circulating cfDNA in human circulation was reported in 1948 by Mandel \& Metais. Two contenders for the main origins of cfDNA are supported to be (i) the cellular breakdown mechanisms and (ii) the active DNA release mechanisms [51]. Moreover, there are various causes of cfDNA release in the mammalian body depending on an organism's health, age, exercises, inflammation and the pathophysiology of a disease [51].

The concentration of the total cfDNA in healthy individuals is on average $30 \mathrm{ng} / \mathrm{mL}$ plasma and ranges from 0 to $100 \mathrm{ng} / \mathrm{mL}$, whereas, in cancer patients, this can be up to $1,000 \mathrm{ng} / \mathrm{mL}$ with an average of $180 \mathrm{ng} / \mathrm{mL}$ [17].

In addition to cfDNA from non-malignant (predominately hematopoietic) cells, blood samples may contain minute amounts of ctDNA derived from primary and metastatic lesions. CtDNA levels in plasma show great variability within and between tumor types [52]. CtDNA represents an opportunity for minimal-invasive monitoring of the disease course and assessment of residual disease after curative surgery [53-55], and may provide a more comprehensive overview of the spectrum of mutations in a patient's tumor.

CtDNA was isolated in blood (plasma and serum) as well as other body fluids such as urine, saliva, cerebrospinal fluid, pleural effusion, ascitic fluid, semen, breast milk, lymphatic and peritoneal fluids, bone marrow aspirates, prostatic fluid, peritoneal lavage, gastric juice, biliary, and stool samples [56].

CtDNA is single- or double-stranded DNA that presents many cancer-associated molecular characteristics, such as single-nucleotide mutations, copy number variations (CNVs), methylation and structural changes or rearrangements [57]. There are three potential origins of ctDNA: (i) apoptotic or necrotic tumor cells; (ii) live tumor cells in tumor tissue; (iii) CTCs [58]. Two are the main processes involved in the release of ctDNA into the blood: (i) passive release of DNA through cell death either by apoptosis or necrosis; (ii) active secretion of DNA by release of EVs [59]. As a consequence of enzymatic cleavage of DNA during apoptosis, the resulting DNA fragments are still wrapped around single nucleosomes and the length plus linker is around 166 or $320 \mathrm{bp}$, if DNA is wrapped around two nucleosomes, up to $1,000 \mathrm{bp}$ if it is released from phagocytosis of necrotic cells. The rate of ctDNA shedding into the circulation depends on the location, tumor burden, size and vascularity of the tumor, cancer stage, cellular turnover, and response to therapy leading to a difference in ctDNA levels from 0.01 to $90 \%$ found in blood [60].

It is estimated that patients with a tumor load of $100 \mathrm{~g}$ in size release $3.3 \%$ of the tumor DNA into the circulation on a daily basis [61] and that the half-life time of ctDNA in the blood circulation ranges from $16 \mathrm{~min}$ to $2.5 \mathrm{~h}$.

\section{Circulating cell-free RNA, circulating tumor RNA and microRNA}

Cell-free circulating RNA (cfRNA) consisting of circulating tumor RNA (ctRNA), mRNA, microRNA (miRNA), and noncoding RNAs can be determined in the plasma of patients for monitoring tumor genetic dynamics. RNA is a relatively unstable molecule, the naked half-life of which in plasma is about $15 \mathrm{~s}$, its stability is enhanced by the association with proteins, proteolipid complexes, and EVs [62].

Circulating RNA has been isolated from blood of patients suffering from several types of malignancies (breast, lung, gastric, renal-cell, bladder cancer, melanoma, and gynecologic malignancies) and has been used as a biological marker either for the early detection and diagnosis of the disease or as a marker of recurrence patterns, survival predictor and follow up [63].

CtRNA is not only used to identify mutations in genes of interest but allows the identification of tumor-specific fusion transcripts or alternative splice events and provides information about relative expression levels of dedicated genes.

Programmed cell death-ligand-1 (PD-L1) expression was detected in plasma of patients with different cancer types (no PD-L1 mRNA was detected in cancer-free people) showing also a high degree of concordance with the expression of PD-L1 protein in tumor tissues. Moreover, both methods were equally predictive of pharmacological response [64, 65].

However, there are difficulties in using mRNA as a biomarker in liquid biopsy, since the reproducibility of cellfree mRNA is limited due to its instability, low abundance, 
and intracellular mRNA contamination from specimen processing [66].

Recently, several studies have focused on miRNAs. miRNAs are released by cells either in association with RNA-binding proteins or packaged inside exosomes, which protect these cell-free miRNAs against RNase activity. Their concentration in blood and other biofluids is higher than mRNA and more stable in cancer patients [67]. Before analyzing miRNAs it is necessary to separate them from contaminants (RNA from coagulation process, platelets, cell debris, proteins, and exosomes), which represent the major drawbacks of using cell-free miRNAs as biomarkers in cancer.

MiRNA expression levels have been proven to be potentially valuable for early diagnosis, prognosis, and prediction of the response to therapy in various types of cancer using multiple analyses of miRNAs [68].

Finally, circular RNAs (circRNAs) have only recently been considered in the oncological field after it was revealed that they are very abundant, highly conserved across species, and show tissue- and developmental stagespecific expression. This tightly regulated, dynamic circRNA expression, in line with the expression of messenger RNAs, microRNAs, and long noncoding RNAs, is altered in both solid tumors and hematologic malignancies and most likely contributes to tumorigenesis [69].

\section{Exosomes}

Exosomes are 40-150 nm EVs of endosomal origin secreted by cells functioning as mediators of intercellular communication.

The exosomal cargo comprises cytoskeletal, transmembrane and thermal shock proteins, lipids, enzymes and nucleic acids, mainly mRNA, miRNA as well as singlestranded and two-stranded DNA [70]. The content of exosomes is dependent on the cell of origin and can be transferred into adjacent or distant recipient cells, modulating their intracellular signaling pathways, gene expression, and phenotype [71]. Moreover, cancer-derived exosomes contribute to the recruitment and reprogramming of constituents associated with the tumor environment [72].

The most commonly used methods for the isolation of exosomes demand successive centrifugation and ultracentrifugation steps to avoid cell contaminants. Magnetic beads coated with antibodies against exosomes markers (mainly tetraspanins), Size-Exclusion liquid Chromatography (SEC), and membrane-binding peptide can also be used on this regard $[73,74]$.
Exosomes are very stable under different storage conditions [75] qualifying them as potential biomarkers to predict cancer burden and impact personalized cancer care.

Since 2008, Skog et al. have demonstrated that circulating serum exosomes are positive for an EGFRvIII mutant/variant [76], typical of a clinical subtype of glioblastoma, when the parental glioblastoma cells also express this mutant/variant. The expression of this mutant/ variant is decisive in determining the therapeutic approach for these patients [77] thus, determining EGFR status from exosomes instead of a tumor biopsy is of immense benefit for patients. Similar applications for exosomes have been described for ovarian cancer [73], melanoma [78] colorectal cancer [79], and prostate cancer [80, 81]. Silva et al. have reported that high levels of exosomes in plasma of patients with colorectal cancer were significantly associated with poorly differentiated tumors and with decreased overall survival (OS) [79] while patients with ovarian cancer exhibit significantly increased levels of serum exosomes compared to benign disease or healthy controls [73]. Moreover, Taylor et al. compared the profile between exosome-derived miRNAs and corresponding tumorderived miRNAs revealing a dysregulated expression of 43 out of 218 detectable miRNAs [73].

Finally, Hoshino et al. demonstrated that the composition of exosomal integrins could predict organ-specific metastasis and that tumor-derived exosomes participate in preparing the pre-metastatic niche [82].

These data suggest a specific selection of miRNAs in tumor-derived exosomes. Exosomes derived miRNAs and mRNA could serve as a useful tool to classify patients into different risk categories to enable a tailored cancer therapy.

\section{Clinical application of liquid biopsy}

\section{Breast cancer}

Breast Cancer (BC) is the most common cancer in females and is still a leading cause of cancer death worldwide. In the last decades, $\mathrm{BC}$ outcomes have been greatly improved as a consequence of the diffusion of population-based screening programs, enabling an even more early diagnosis (i.e., the identification of the disease at a regional stage), and of the availability of multidisciplinary therapeutic programs [83]. In addition, the increasing knowledge of $\mathrm{BC}$ molecular features is driving the development of novel and even more personalized diagnostic, prognostic, and therapeutic tools that are impacting both patients' survival and quality of life [84]. In this context, as stated 
also for other cancers, liquid biopsy (including both CTCs and ctDNA) has emerged as a new attractive opportunity, able to overcome some limits of traditional biopsy and to provide a more representative picture of disease heterogeneity. To date, liquid biopsy has shown its potentialities for $\mathrm{BC}$ biomarkers detection, disease recurrence detection, drug resistance identification, and prognostic stratification [85]. In particular, CTCs have been already reported to independently impact on $\mathrm{BC}$ disease free survival and $\mathrm{OS}$ in both metastatic and non-metastatic cancers [86]. Lucci et al. analyzing 302 non-metastatic BC patients, demonstrated that the detection of one or more CTCs correlated with early recurrence and OS reduction [87]. Rack et al. assessed in a large cohort of patients the potential role of CTCs as prognostic markers already at BC diagnosis for the stratification of patients requiring adjuvant therapy [88]. A subsequent meta-analysis, by analyzing 21 studies on BC patients treated by neoadjuvant therapy, found that CTC number evaluation is an independent prognostic factor for early BC [89]. Finally, Trapp and colleagues have shown that the persistence of CTCs two years after chemotherapy is correlated to a decreased OS, suggesting that CTC monitoring may improve $\mathrm{BC}$ patients' surveillance programs [90]. However, more data are available on the possible utility of CTCs in metastatic cancers. Indeed, MBC can occur both as first presentation and as recurrent disease, and is still affected by a high mortality rate; thus, new tools for patients' prognostic stratification are required. Almost 15 years ago, Cristofanilli and colleagues demonstrated that the identification of $\geq 5 \mathrm{CTCs} / 7.5 \mathrm{~mL}$ blood was predictor of a worse outcome in $\mathrm{MBC}$ patients, irrespective of other parameters [91]. Subsequently, Budd et al. showed that CTC count is a better predictor of MBC OS than imaging tool [92]. Similarly, a multicenter study assessed that serial CTC count is more effective than conventional serum antigens in the early detection of MBC therapy failure [93]. Serial CTC evaluations have also shown their utility in MBC therapy monitoring [94]; an international trial reported that a modification of the therapy, not able to reduce the CTC number, had no effects on patients' OS [95]. In this regard, another interventional trial is evaluating the possibility to use CTCs to stratify MBC patients for chemotherapy or hormone therapy [96]. The preliminary results suggested that the switch from hormone therapy to chemotherapy driven by CTC count is able to ameliorate patients' free survival [96]. A consensus paper from an International panel of experts has recently evaluated the possible use of CTCs in clinical settings for MBCs staging [97]. By retrospectively analyzing a total cohort of 2,436 MBC patients, the authors classified stage IV tumors as "aggressive" and "indolent" based on CTC count $\geq 5 / 7.5$ or
$<5 / 7.5 \mathrm{~mL}$, respectively. Interestingly, they found that indolent patients had a longer OS than the aggressive ones, independently from clinical and molecular features, so that they conclude that CTC count should be used for advanced BC staging [97].

In addition to the quantitative evaluation, also the detection of specific CTC features may have a clinical utility. Indeed, it has been proven that, during treatment, ER+ MBCs can develop ER-CTCs; it has been hypothesized that this phenomenon may reflect the acquisition of therapy resistance by the primary tumor [98]. An interventional trial is currently testing the possibility of using the HER2 status of CTCs to stratify MBC patients [99]. Moreover, СTC expression of protein death-1 ligand correlates with MBC OS, suggesting that CTC evaluation may be useful to predict the sensitivity to specific immunotherapies [100]. Finally, Koch and colleagues have recently reported for the first time the establishment of a CTC line from an ER+ MBC patient: this model may provide novel tools for the study of the molecular bases of MBC [101]. It has to be noticed, that even if most of the studies on CTCs uses blood as biological sample, also other fluids may be useful. A recent study by Malani et al. reports the identification of CTCs in the cerebrospinal fluid of $\mathrm{BC}$ patients with leptomeningeal metastases [102]. This finding will open the way to further studies to assess the clinical relevance of specific body fluids evaluation to stratify MBC patients.

In addition to CTCs, also the use of cfDNA/ctDNA has been largely investigated in $\mathrm{BC}$. In particular, the identification of tumor-specific mutations in ctDNA has been related to tumor burden and possible clinical outcomes $[85,86]$. Moreover, high levels of ctDNA have been associated with a more aggressive and potentially resistant disease, both in early and metastatic BCs $[85,86]$. Considering the low amount of ctDNA, several issues are related to technical aspects in order to ensure a reliable ctDNA detection [103]. In addition to quantitative evaluation, as stated above, the identification of ctDNA mutations can be useful to predict therapy sensitivity. In this context, Ma et al. found that HER2 amplificated ctDNA highly correlates with the development of anti-Her2 therapy resistance [104]. A subsequent study confirmed that HER2 amplification in ctDNA and hormone status can predict primary resistance to trastuzumab emtansine in MBC patients [105]. Similarly, the identification of ESR1 gene mutations in ctDNA from MBC patients has been related to the development of aromatase inhibitor treatment resistance [106]. The recent approval of alpelisib, a PI3K inhibitor, opened the door for the use of liquid biopsy in $\mathrm{BC}$ as a clinically useful test. The SOLAR-1 trial demonstrated the efficacy of the new experimental drug in $\mathrm{MBC}$ patients with 
a PI3K mutation found in tissue or in plasma ctDNA. Moreover, the final OS data showed an increased clinical benefit in patients with PI3KCA mutation in plasma ctDNA vs tissue (9.2 vs. 7.9 months) [107]. The introduction of new standards of treatment in BC (CDK4/6 inhibitors and PI3K inhibitors), increased the use of liquid biopsy in order to identify new biomarkers of response/resistance to therapy. In this view, it has been demonstrated that the analysis of PI3K in ctDNA is not only a useful biomarker to identify responders to alpelisib, but is also a negative predictive biomarker for CDK4/6 inhibitors. In detail, a recent study demonstrated that patients carrying a PI3K mutation in ctDNA have a shorter PFS to palbociclib/ribociclib compared to non-mutant PI3K patients. Moreover, the PI3K status was strongly associated to Ki67\% expression in primary lesions [108]. Resistance to CDK4/6 inhibitors is claiming great attention, and several studies are investigating how liquid biopsy may help in identifying possible biomarkers of resistance, using either ctDNA $[109,110]$ or exosomes [111]. Interestingly, by comparing cfDNA mutational status and CTCs from MBC patients, Shaw et al. verified that cfDNA mutational burden reflects CTC heterogeneity [112]. The availability of next generation sequencing (NGS)-based methods has enhanced the possibility to characterize ctDNA mutational status. In this context, Davis et al. by analyzing a 180 gene panel in 22 MBC patients, not only detected ctDNA variants in almost all patients, suggesting their monitoring to evaluate disease progression, but also correlated these alterations to CTC count [113]. Keup et al. used a custom panel to analyze the cfDNA of $44 \mathrm{MBC}$ patients and identified several pathogenic variants of potential interest for disease progression monitoring [114]. Finally, Gerratana et al. have recently evaluated the performance of a novel NGS-based tool, PredicinePLUS, with respect to those of the CLIA-validated Guardant $360^{\mathrm{TM}}$ in detecting genomic alterations in MBC patients. Their data indicate that results of different NGS-based tests may be comparable if pre-analytic variables related to sample collection and management are controlled [115]. Taken together, all these data show that CTCs and/or ctDNA can be considered reliable biomarkers for both early $\mathrm{BC}$ and $\mathrm{MBC}$, and should be included in $\mathrm{BC}$ evaluation programs. Of course, methodological issues still need to be assessed before their diffusion in routine diagnostic settings.

\section{Colorectal cancer}

Colorectal cancer is a high prevalence malignant disease often diagnosed in late stage and with a severe impact on the population. Liquid biopsy approach to this disease could improve prognosis and quality of life [116]. CTCs have been investigated in colorectal cancer with different approaches, based on both physical properties of CTCs or marker expression [116]. From a clinical point of view, CTCs have been explored as biomarkers for screening, auxiliary staging of colorectal cancer, prognosis, monitoring drug resistance, and guiding medication as well as monitoring tools for minimal residual disease (MRD) [117]. Some studies explored the possibility of using CTC detection for the screening of colorectal cancer with encouraging results, but the sensitivity of the currently available techniques for CTC identification is still insufficient for enabling early diagnosis, since CTCs are infrequent in early stages of disease [118, 119]. A few studies investigated the clinical significance of CTCs in a diagnostic setting in colorectal cancer revealing a concordance between CTC enumeration with disease stage $[120,121]$ and the size of the primary tumor [120] as well as a relationship between liquid and solid biopsy in cell morphology [122].

CTC based liquid biopsy could help treatment selection in colorectal cancer, in particular for the assessment of the presence of KRAS or BRAF mutations conferring resistance to treatment with anti-EGFR monoclonal antibodies. Different authors demonstrated the feasibility of CTC mutational analysis [123-125], but so far cf DNA has been preferred to CTCs as a substrate to investigate the presence of such mutations, probably due to the challenging task still represented by CTC enrichment, isolation and analysis. The major part of the studies involving CTCs in colorectal cancer demonstrated the prognostic significance of the presence and number of CTCs, starting from the first study by the CellSearch system [38], establishing a cutoff of three CTCs/7.5 mL blood for a worse prognosis in metastatic colorectal cancer (mCRC) patients, thence the FDA approval of CTC counting by CellSearch as a diagnostic tool in metastatic colon cancer. A recent report of the results of the VISNU clinical trial assesses that CTC count by CellSearch above the cutoff in mCRC patients is associated with clinical or pathologic features indicating a poor prognosis such as worse performance status, stage IV at diagnosis, at least three metastatic sites and elevated CEA levels [126].

A review on RT-PCR based detection of CTCs demonstrated that CTCs are a prognostic factor also in non-mCRC and that the use of CTCs is a prognostic indicator of metastatic disease prior to current diagnostic methods [127]. A recent meta-analysis on the prognostic role of CTCs in this pathology revealed that CTCs at baseline or during treatment are independent predictors of overall and progression-free survival independently from the detection method used [128]. 
The presence of CTC clusters in the circulation has been detected in colon cancer $[129,130]$ and associated to a worse prognosis with a shorter survival for patients presenting CTM than for those with isolated CTCs [26].

Another potential clinical application of CTC detection, counting and analysis is therapy monitoring, as reported by different studies on colorectal cancer. CTCs, in fact, have been demonstrated to be a good surrogate marker in advanced colorectal cancer to identify patients responding to chemotherapy or with a risk of a therapy failure [131], as well as in predicting response to further chemotherapy and surgical treatment in patients with unresectable metastases from colorectal cancer [132]. Moreover, the possibility to assess the EGFR status in CTCs might provide an early opportunity to predict target therapy response [131]. The analysis of KRAS mutations in serial CTC samples enriched by CellSearch revealed that CTCs exhibited different mutational statuses of KRAS during treatment, opening the perspective of predicting the response of patients to targeted therapy [133]. CTCs have shown a potential to detect MRD in monitoring patients post-surgery [134-136].

A new research field is represented by the analysis of CTCs from cancer patients at the single cell level to dissect tumor heterogeneity through the liquid biopsy.

The mutational status of single CTCs from colon cancer patients was investigated demonstrating the feasibility of pure CTC characterization and revealing heterogeneity in KRAS status among CTCs within a patient and discordance between CTCs and primary tissue $[137,138]$.

Comprehensive genomic profiling of CTCs using array comparative genomic hybridization and next-generation sequencing (NGS) was performed on single CTCs from stage IV colorectal carcinoma patients finding the same mutations in known driver genes found in the primary tumor and metastases also at subclonal level [139]. Highresolution cytomorphometric characterization performed by the High-Definition Single Cell Analysis workflow on CTCs and solid biopsies from patients affected by mCRC revealed high inter- and intra-patient pleomorphism with a high correlation between CTCs and tissue cells for morphometric variables, suggesting that circulating cells do not represent distinct subpopulations from the solid tumor, thus demonstrating that CTCs can be informative biomarkers [122]. Recently, the metabolic fingerprint of single CTCs from colon cancer patients was obtained by integrating live single-cell mass spectrometry and a microfluidics-based CTC enrichment technique followed by single cell picking by a micromanipulator [140].

Despite the promising results of the researches on CTCs, a concrete application of CTC analysis to colorectal cancer patients' management in still missing: standardization of the (pre)-analytical procedures and specific clinical trials will help to fill this gap.

In addition to CTCs also the use of cfDNA/ctDNA has been strongly investigated in CRC. In contrast to CTCs, ctDNA gives information about tumor burden and should be detected in smaller blood amounts compared with CTCs [141]. Some studies suggested that ctDNA was more sensitive for the detection of mCRC than CTCs [142]. Total cfDNA and ctDNA were elevated in the peripheral blood of CRC patients compared to both healthy controls and patients with inflammatory bowel disease [143]. Both variant alleles and epigenetic markers (CpG island methylation) are relevant in the detection and interpretation of ctDNA in CRC [144]. Indeed, methylation pathways represent a promising biomarker for early diagnosis of cancer [145-148] and could be the most promising candidates for a blood-based CRC-screening modality [149]. SEPT9 was one of the most widely studied gene promoters in CRC [150] however, Sun et al. demonstrated by a meta-analysis that it did not distinguish optimally CRC, polyps or adenomas [151]. Moreover, Nian et al. mentioned in their metaanalysis that they founded different sensitivities from oriental and occidental populations. In particular, the results showed that Asia Group had higher sensitivity than other continents and that it might have occurred due to the potential racial differences and kit variations [152].

Other recently studied ctDNA markers [153, 154], showed a lower sensitivity for early-stage disease than for advanced stages [155]. In 2018 a joint review by the American Society of Clinical Oncology (ASCO) and the College of American Pathologists (CAP) concluded that currently there is little evidence for the clinical validity of ctDNA for CRC screening and early-stage cancer [156]. Nevertheless, ctDNA has been clinically utilized to improve disease management of mCRC patients (1) as a predictive biomarker for treatment selection: ctDNA analysis of KRAS mutations are currently being considered as a clinically applicable alternative to tissue DNA mutation analysis; (2) as a monitoring tool for treatment response [26]: the ctDNA analyses can be used as a first step towards determination of primary resistance to anti-EGFR treatment [157] or to HER2 inhibitors [158] and generally, quantitative increases of ctDNA reflect disease progression. The analysis of ctDNA in colorectal cancer is also showing promising results for a treatment rechallenges strategy. In particular, the CRICKET study was a phase II trial aimed at prospectively assess the efficacy of cetuximab plus irinotecan as third-line treatment for RAS and BRAF wild-type mCRC patients, who were sensitive to first-line irinotecan- and cetuximabbased therapy and then resistant. The study demonstrated 
that a rechallenge strategy with cetuximab and irinotecan may be active and that the evaluation of RAS status on ctDNA might be helpful in selecting candidate patients [159].

Liquid biopsy has demonstrated promise in detecting MRD or recurrence during the surveillance of colon cancer. Standard post-treatment surveillance requires the use of non-specific serum markers (CEA), endoscopy, and an abdominopelvic CT scan. Compared to CT imaging, cancerspecific ctDNA mutations are a more direct biomarker that represents tumor burden, ctDNA being capable to detect disease recurrence with lead times of 2-15 months compared to CT imaging [160]. These observations need validation in larger studies, to confirm that detection of disease progression by ctDNA analyses precedes such detection by CT imaging.

\section{EGFR positive lung carcinoma}

The advances in the molecular biology of lung cancers made possible the characterization of a high degree of molecular heterogeneity, over time and across different disease sites [161, 162]. Spatial and temporal heterogeneities are often responsible for many critical issues in the diagnosis and treatment of cancer patients, requiring the use of new, fast, more accurate, sensitive, and specific techniques, able to be a valuable addition to the available assessment methods in guiding the therapy management that best fits patient's individuality and tumor singularity. In today's era of precision oncology, minimally invasive liquid biopsies represent an extremely appealing approach to be implemented both at pre-treatment baseline and longitudinally as predictive markers during the course of tyrosine kinase inhibitors (TKI) treatment $[53,59,62$, 163-167].

To date, although LB should not be considered as a substitute for tissue biopsy for early diagnosis [168], its aid seems to confer an advantage on the initial molecular investigation [169]. About that, cfDNA levels have been described to be useful to detect and diagnose lung cancer at an early stage [170]. Previous researches founded that cancer patients had higher plasma-derived cfDNA levels than healthy controls $[171,172]$, and a study analyzing the diagnostic value of cfDNA in 60 non-small cell lung cancer (NSCLC) patients and 40 individuals with chronic obstructive pulmonary disease showed that cfDNA levels have an accuracy rate of $83.6-92.1 \%$ (depending on the fragments length) in diagnosis [173].

Even if liquid biopsy still needs to be validated as a diagnostic biomarker, it constitutes a very appealing option to identify biomarkers of sensitivity or resistance, and to monitor mechanisms of resistance [174-177]. Profiling of patients who progressed to anti EGFR TKIs revealed that the majority of patients acquire secondary EGFR mutations such as T790M, which induces first- and second-generation EGFR-TKIs resistance by increasing ATP affinity and steric hindrance [178]. One of the first studies that monitored the development of drug resistance by serial analysis of cfDNA dates to 2009. Kuang and colleagues [174] isolated ctDNA from 54 patients with metastatic NSCLC and known clinical response to gefitinib or erlotinib. The authors identified EGFR T790M in 15/28 patients with prior clinical response, 4/14 with prior stable disease and $0 / 12$ with prior progressive disease or untreated with gefitinib/erlotinib, thus suggesting ctDNA molecular analysis as a viable option to monitor emerging resistance mutations and direct the course of subsequent therapy. In 2013, also the Rosenfeld's research group [179] reported an increase of T790M mutant allele fraction following gefitinib treatment in the lung cancer patient. Likewise, in 2016, Sundaresan and collaborators [175] stressed T790M genotyping from CTCs and ctDNA, comparing it with data from simultaneously collected tumor biopsies in 40 patients with EGFR-mutant lung cancers progressing on TKIs. Although CTC- and ctDNA-based genotyping were each unsuccessful in $20-30 \%$ of cases, the two assays together enabled genotyping in all patients with an available blood sample, and they identified the T790M mutation in 14 (35\%) patients in whom the concurrent biopsy was negative or indeterminate. Even Oxnard et al. [176] showed that $\sim 30 \%$ of patients who test negative for the presence of $\mathrm{T} 790 \mathrm{M}$ in tissue are positive in plasma $(-/+)$. However, albeit lower than tissue+/plasma+ or tissue+/plasma-, these patients benefit from osimertinib treatment, establishing that these apparent false positives are not sequencing errors but the result of tumor heterogeneity [176]. T790M relative fractional abundance (FA) can also be an additional tool in interpreting a plasma test, by informing the clinician whether T790M is the dominant mechanism of resistance or a subclonal phenomenon within heterogeneous biology (i.e., T790M FA $<10 \%)$. The detection of high EGFR driver mutation-related FA could confirm that ctDNA is shed by the tumor and would make a false negative T790M result more likely than a true negative, although its presence as a minor subclone is still possible. Overall, $\sim 30 \%$ of $\mathrm{T} 790 \mathrm{M}+$ tissues are missed by plasma due to a lack of sensitivity/DNA shedding [176]. A negative test for both driver and T790M mutations is not informative because it could potentially be linked to the absence of shedding DNA and indicates the need for tissue biopsy. However, a negative result should 
always be validated by tissue sampling, which will enable the detection of other mechanisms of resistance, not covered by currently approved cfDNA assays (e.g., histotype transformation [180, 181], MET [182], and HER2 [183] amplification, or PIK3CA mutations [184]).

Besides T790M mutation, C797S also hinders thirdgeneration EGFR-TKI inhibition by preventing irreversible binding between the small molecule and the ATP-binding pocket [185]. And on that note, Thress and colleagues confirmed its emergence as a specific mechanism of acquired resistance to osimertinib by screening cfDNA from fifteen EGFR T790M+ patients during treatment [186].

Furthermore, in addition to such well-known EGFR tertiary mutations, both $A L K$ rearrangements and point mutations, ascribed as responsible for respective TKIs resistance, were successfully evaluated in plasmatic cfDNA of lung cancer patients [187-190].

In addition, the recent use of immunotherapy in lung cancer has raised new needs. Many of the predictive biomarkers are currently being used or explored for use with immunotherapy [191]. As an example, in routine practice, immunohistochemical (IHC) assessment of tumor tissue PD-L1 expression is established as an accompanying predictive marker of response to first-line (tumor proportion score, TPS $\geq 50 \%$ ) [192] or second-line (TPS $\geq 1 \%$ ) [193] pembrolizumab in metastatic setting, as well as to secondline durvalumab (TPS $\geq 1 \%)$ [194, 195] in patients with locally unresectable advanced NSCLC. Nonetheless, the use of PD-L1 IHC involves some technical and biological challenges, too. One major issue concerns heterogeneous intra- and inter-tumor expression [196, 197]. Moreover, small bronchial or transthoracic biopsies may underestimate the PD-L1 status and patients may not receive the treatment due to sampling bias [196]. Therefore, given these limits, and given the promising results obtained from LB in targeted therapies, its use into the domain of immunotherapy is unsurprising. For instance, CTCs are derived from more than one tumor site and should provide a better overall representation of PD-L1 expression in metastatic setting [198], although other challenges limit their application as a predictive marker of response to ICIs. CTCs can be isolated based on size and deformability [199-203], or by using antigen-specific filters (most often epithelial cell adhesion molecule, EpCAM) [204-206]. Although EpCAM-based enrichment methods would allow detection and characterization of large and small CTCs, cells achieving epithelial-mesenchymal transition (EMT) as CTCs with high PD-L1 expression often do - lose EpCAM expression and bypass the antigen-dependent filter. Such CTCs could therefore only be detected by antigenindependent methods [207]. However, the morphology classification of CTCs also has limitations, such as the recognition of monocytes [208] and other circulating myeloid-derived suppressive cells (CD45-, cytokeratin+) [209] which express PD-L1, as false-positive CTCs. Furthermore, it remains to be clarified whether PD-L1 is expressed on all CTCs or in some subpopulations; whether prognosis and predictive response to immunotherapy is correlated with CTC-derived PD-L1 expression at baseline or during follow-up of treated patients; and whether the expression of PD-L1 in CTCs is related to synchronously matched tissue biopsies. Only Ilie et al. [198] were able to show good concordance between tissue and CTCs, but the rate of positive samples was low and correlation with response to PD1/PD-L1 inhibitors could not be investigated. Apart, recent work by Lee and Rho's groups reports that lung cancer cells release PD-L1+ EVs into the circulation, mainly exosomes, to systemically suppress the immune system [210]. This finding suggests that PD-L1+ EVs are also able to counteract the immune pressure at the effector stage and offer a novel marker for immunotherapy beside CTCs.

Moreover, despite a broadly and functional proinflammatory environment, tumor immunogenicity is also mandatory [211]. The indirect expression of tumor immunogenicity is the tumor mutational burden (TMB) [212]. TMB can be assessed by quantifying the number of non-synonymous mutations across the whole exome or in a defined gene panel through NGS [213]. TMB analysis in ctDNA and molecular cargo of peripherical tumor microenvironment-derived exosomes, potentially adding new LB candidates to a growing list of blood tests to manage cancer patients.

\section{Melanoma}

Melanoma is one of the most aggressive cancers and is known for its rapid progression and poor prognosis in the advanced stages. Its incidence is steadily increasing among Caucasian populations [214]. Main risk factors include exposure to ultraviolet radiation, a history of sunburn, multiple common and atypical nevi, fair skin type, and genetic predisposition. Although it can be surgically cured if detected at early stages, survival rates are drastically low in the advanced disease [215]. Melanoma arises through the gradual accumulation of molecular abnormalities and shows the highest mutation rate among all cancers [216]. The most significant driver mutations occur in BRAF, NRAS, NF1, and KIT genes [217]. Activating BRAF mutations are present in about $50 \%$ of cases, mainly at codon 600 with the V600E change, while oncogenic NRAS 
mutations are found in $15-25 \%$ of melanomas. Mutations in the other genes are less frequent.

Treatment decision involves molecular analysis of driver mutations in the primary tumor or metastatic tissues, but the huge heterogeneity of the molecular changes occurring during the disease course make melanoma management difficult [218]. Since 2011, few therapies approved for treatment of stage III and IV melanoma patients and in adjuvant setting have been introduced in clinical practice. The use of target therapies (anti-BRAF and anti-MEK drugs) and immunotheraphies have improved the one year survival rate up to $75 \%$ [218]. However, the emergence of drug resistance in the majority of patients for MAPK inhibitors and low but durable response rates for single-agent immune checkpoint inhibitors represent major limitations. Consequently, reliable methods for monitoring disease progression or treatment resistance are necessary.

Liquid biopsy has long been considered as a promising non-invasive method in melanoma management [219] and might represent a valuable tool especially in high-risk patients with advanced stage tumor (IIc, III, and IV), particularly for patients with No Evidence of Disease (NED) or MRD status [220, 221].

The detection of CTCs and/or ctDNA in blood of melanoma patients might help in stratifying patients for therapies, predicting clinical outcomes, monitoring response, and progression.

The existence of circulating melanoma cells was described for the first time in 1991 and since then many studies using different detection approaches have been performed, with conflicting results [221]. The main issue is that melanoma cells do not express EpCAM that is the classical marker of most CTC isolation strategies [220]. Therefore, alternative approaches based on makerdependent-melanoma-specific antigens like MART-1, MAGE-A3, PAX-3, GalNac-T, HMW-MAA,CD146 (MelCAM), and MCAM- or marker-independent (based on large size or density of primary melanoma cells) strategies have been proposed [222]. The most innovative technologies of cellcapture include microfluidic chips and biosensors, the magnetic CellSearch ${ }^{\circledR}$ Circulating Melanoma Cell Kit, the dual-step protocol immune-magnetic sorting and subsequent dielectrophoretic DEPArray separation, and a new in vivo photoacoustic flow cytometry platform called "Cytophone" [220, 222, 223].

The presence of CTCs has been associated with tumor burden, as well as with decreased disease-free and OS rates in several studies [220, 221, 224]. More recently, the expression of PD-L1 on CTCs has been showed to predict the response to the anti-PD-1 pembrolizumab treatment in advanced melanoma [225]. Instead, the utility of melanoma CTCs for the identification of actionable mutations is limited, since the use of enrichment methods can lead to the loss of CTC subpopulations, representing a bias in molecular definition of the disease [219].

To date, 12 trials registered in the ClinicalTrials.gov database are evaluating the potential clinical application of melanoma CTCs. The majority of them are studying CTCs as biomarkers for monitoring therapy response and for predicting failure before clinical relapse, while the others are evaluating the association of CTCs with OS in patients with metastatic melanoma.

Despite several experimental evidences, to date the utility of melanoma CTCs in clinical routine is still unclear due to the lack of robust and consistent results. Indeed, the great diversity of markers used for enrichment, their low specificity, and the multiplicity of technical procedures reduces the significance of the obtained results. In addition, as melanoma is a highly heterogeneous tumor, melanoma CTCs display different phenotypes and functional states resulting in expression of different markers. Interestingly, Gorges et al. recently demonstrated that the mutational status of melanoma cells might influence the volume of CTCs and the expression of surface markers, representing a threatening bias for the clinical use [226].

In addition to the direct detection of melanoma CTCs, indirect analysis of circulating nucleic acids has been studied. Indeed, the high prevalence of oncogenic hot spot mutations and the availability of several highly sensitive technologies make melanoma an ideal candidate for the use of ctDNA as a biomarker.

The analysis of ctDNA in melanoma patients, includes the detection of typical mutations in BRAF and NRAS genes, microsatellite alterations and epigenetic modifications such as DNA methylation [220]. CtDNA evaluation has been proposed for the management and follow-up of patients with melanoma. Overall, the use of ctDNA for diagnostic purpose is not the priority in melanoma, since there is usually enough tumor tissue available for genetic analyses; therefore it is limited to cases of scarce material or when additional clinically relevant information, as clonality or tumor heterogeneity, need to be considered [219]. Monitoring melanoma course and predicting treatment outcomes represent the preferred uses of ctDNA for this cancer type.

Several studies demonstrated a prognostic value, as high levels of ctDNA bearing the BRAFV600E mutation at melanoma diagnosis have been correlated with shorter PFS and OS [221, 227, 228]. In addition, the increase of ctDNA with the same mutation of the primary tumor might reflect melanoma progression also by preceding radiological 
detection, and reveal mechanisms of resistance [229]. In patients with advanced disease, melanoma ctDNA seems to be also a good predictor of the response to PD- 1 or CTLA-4 inhibitors [230, 231]

Finally, the evaluation of methylation-specific ctDNA markers, as the detection of RASSF1A, tissue factor pathway inhibitor 2 (TFPI2) hypermethylation, has been linked with the state of disease, non-response and shorter OS and with pre-treatment CTC counts [232-234]. Currently, 22 clinical trials are registered in the ClinicalTrials.gov database aiming to study either the prognostic value of BRAF- or NRAF-mutated ctDNAs, their modulation during treatments and the standardization of methods for ctDNA quantification and mutation detection. Interestingly, although total cfDNA cannot be considered a melanomaspecific biomarker, Varaljai et al. in 2020, demonstrated that high levels of cfDNA can provide information on tumor load, risk of progression and risk of death irrespective of the tumor genotype [235].

Regarding other circulating biomarkers, several efforts have been made to identify circulating miRNAs that may be used for diagnostic purpose [236]; however, the variety of detection and normalization methods prevents the individuation of a single or a panel of c-miRNAs useful in clinical setting. A study investigating the association between PD-L1 mRNA in plasma-derived exosomes and response to nivolumab and pembrolizumab in patients with melanoma, demonstrated that exosomal PD-L1 is significantly associated with response to immunotherapy, being exosomes-PD-L1 levels associated to the patients' outcome [237].

The implications of ctDNA in clinical routine of melanoma patients remain controversial. The limitations are mainly due to scarce specificity and sensitivity of different detection approaches, lack of standardization that introduce experimental bias and prevents obtaining robust data, elevated economic costs [219]. An additional challenge is the absence of tumor specificity of mutations, being the most frequent BRAF-V600E change present only in $40-50 \%$ of melanomas and, perhaps more importantly, it is present also in more than $80 \%$ of benign melanocytic nevi. Finally, whereas the significance of ctDNA is more evident in the management of advanced melanoma patients, its clinical utility in stage I/II and NED patients still remains unknown.

\section{Conclusions}

In the last decade liquid biopsy has emerged as a novel, non-invasive, powerful tool able to provide important information regarding the molecular features of solid tumors. Indeed, CTCs, as well as cfDNA, ctDNA, and exosomes, are showing their potentialities in allowing realtime cancer monitoring, tumor staging and the presence of sensitivity and/or resistance to specific therapies. To date, liquid biopsy has been successfully used in patients affected by melanoma, breast, colorectal, and lung cancer as reviewed above. Thus, it is reasonable to suppose that, once methodological procedures will be standardized and harmonized across laboratories, liquid biopsy-based evaluations will be even more used in routine settings.

Research funding: None declared.

Author contributions: All authors have accepted responsibility for the entire content of this manuscript and approved its submission.

Competing interests: Authors state no conflict of interest.

\section{References}

1. Shin SH, Bode AM, Dong Z. Precision medicine: the foundation of future cancer therapeutics. NPJ Precis Oncol 2017;1:12.

2. Bailey AM, Mao Y, Zeng J, Holla V, Johnson A, Brusco L, et al. Implementation of biomarker-driven cancer therapy: existing tools and remaining gaps. Discov Med 2014;17:101-14.

3. Domínguez-Vigil IG, Moreno-Martínez AK, Wang JY, Roehrl MHA, Barrera-Saldaña HA. The dawn of the liquid biopsy in the fight against cancer. Oncotarget 2017;9:2912-22.

4. Bedard PL, Hansen AR, Ratain MJ, Siu LL. Tumor heterogeneity in the clinic. Nature 2013;501:355-64.

5. Galbiati S, Damin F, Ferraro L, Soriani N, Burgio V, Ronzoni M, et al. Microarray approach combined with ddPCR: an useful pipeline for the detection and quantification of circulating tumour DNA mutations. Cells 2019;8:769.

6. Sholl LM, Aisner DL, Allen TC, Beasley MB, Cagle PT, Capelozzi VL, et al. Liquid biopsy in lung cancer: a perspective from members of the Pulmonary Pathology Society. Arch Pathol Lab Med 2016;140: 825-9.

7. Ilié M, Hofman P. Pros: can tissue biopsy be replaced by liquid biopsy? Transl Lung Cancer Res 2016;5:420-3.

8. Joosse SA, Pantel K. Tumor-educated platelets as liquid biopsy in cancer patients. Canc Cell 2015;28:552-4.

9. Oxnard GR, Paweletz CP, Kuang Y, Mach SL, O’Connell A, Messineo MM, et al. Noninvasive detection of response and resistance in EGFR-mutant lung cancer using quantitative nextgeneration genotyping of cell-free plasma DNA. Clin Canc Res 2014;20:1698-705.

10. Mathai RA, Vidya RVS, Reddy BS, Thomas L, Udupa K, Kolesar J, et al. Potential utility of liquid biopsy as a diagnostic and prognostic tool for the assessment of solid tumors: implications in the precision oncology. J Clin Med 2019;8:373.

11. Castro-Giner F, Gkountela S, Donato C, Alborelli I, Quagliata L, Ng $\mathrm{CKY}$, et al. Cancer diagnosis using a liquid biopsy: challenges and expectations. Diagnostics 2018;8:31. 
12. Arneth B. Update on the types and usage of liquid biopsies in the clinical setting: a systematic review. BMC Canc 2018;18: 527.

13. Mino-Kenudson, Cons M. Can liquid biopsy replace tissue biopsy?-the US experience. Transl Lung Cancer Res 2016;5: 424-7.

14. Alix-Panabières C, Pantel K. Circulating tumor cells: liquid biopsy of cancer. Clin Chem 2013;59:110-8.

15. Paterlini-Brechot $P$, Benali NL. Circulating tumor cells (CTC) detection: clinical impact and future directions. Canc Lett 2007; 253:180-204.

16. Rossi E, Fabbri F. CTCs 2020: great expectations or unreasonable dreams. Cells 2019;8:989.

17. Fernández-Lázaro D, García Hernández JL, García AC, Córdova Martínez A, Mielgo-Ayuso J, Cruz-Hernández JJ. Liquid biopsy as novel tool in precision medicine: origins, properties, identification and clinical perspective of cancer's biomarkers. Diagnostics 2020;10:215.

18. Joosse SA, Gorges TM, Pantel K. Biology, detection, and clinical implications of circulating tumor cells. EMBO Mol Med 2015;7: 1-11.

19. Bankó P, Lee SY, Nagygyörgy V, Zrínyi M, Chae CH, Cho DH, et al. Technologies for circulating tumor cell separation from whole blood. J Hematol Oncol 2019;12:48.

20. Shen Z, Wu A, Chen X. Current detection technologies for circulating tumor cells. Chem Soc Rev 2017;46:2038-56.

21. Lei KF. A review on microdevices for isolating circulating tumor cells. Micromachines 2020;11:531.

22. Aceto N. Bring along your friends: homotypic and heterotypic circulating tumor cell clustering to accelerate metastasis. Biomed J 2020;43:18-23.

23. Amintas S, Bedel A, Moreau-Gaudry F, Boutin J, Buscail L, Merlio JP, et al. Circulating tumor cell clusters: united we stand divided we fall. Int J Mol Sci 2020;21:2653.

24. Aceto N, Bardia A, Miyamoto DT, Donaldson MC, Wittner BS, Spencer JA, et al. Circulating tumor cell clusters are oligoclonal precursors of breast cancer metastasis. Cell 2014;158:1110-22.

25. Wang C, Mu Z, Chervoneva I, Austin L, Ye Z, Rossi G, et al. Longitudinally collected CTCS and CTC-clusters and clinical outcomes of metastatic breast cancer. Breast Canc Res Treat 2017;161:83-94.

26. Zhang D, Zhao L, Zhou P, Ma H, Huang F, Jin M, et al. Circulating tumor microemboli (CTM) and vimentin+ circulating tumor cells (CTCs) detected by a size-based platform predict worse prognosis in advanced colorectal cancer patients during chemotherapy. Canc Cell Int 2017;17:6.

27. Zeinali M, Lee M, Nadhan A, Mathur A, Hedman C, Lin E, et al. High-Throughput label-free isolation of heterogeneous circulating tumor cells and CTC clusters from non-small-cell lung cancer patients. Cancers 2020;12:127.

28. Xu Y, Qin T, Li J, Wang X, Gao C, Xu C, et al. Detection of circulating tumor cells using negative enrichment immunofluorescence and an in situ hybridization system in pancreatic cancer. Int J Mol Sci 2017;18:622.

29. Hai P, Zhou Y, Zhang R, Ma J, Li Y, Shao JY, et al. Label-free highthroughput detection and quantification of circulating melanoma tumor cell clusters by linear-array-based photoacoustic tomography. J Biomed Optic 2017;22:41004.

30. Mazzini C, Pinzani P, Salvianti F, Scatena C, Paglierani M, Ucci F, et al. Circulating tumor cells detection and counting in uveal melanomas by a filtration-based method. Cancers 2014;6: 323-32.

31. Umer M, Vaidyanathan R, Nguyen NT, Shiddiky MJA. Circulating tumor microemboli: progress in molecular understanding and enrichment technologies. Biotechnol Adv 2018;36:1367-89.

32. Sarioglu AF, Aceto N, Kojic N, Donaldson MC, Zeinali M, Hamza B, et al. A microfluidic device for label-free, physical capture of circulating tumor cell clusters. Nat Methods 2015;12:685-91.

33. Weth A, Krol I, Priesner K, Donato C, Pirker S, Wolf C, et al. A novel device for elimination of cancer cells from blood specimens. Sci Rep 2020;10:10181.

34. Cabel L, Proudhon C, Gortais H, Loirat D, Coussy F, Pierga JY, et al. Circulating tumor cells: clinical validity and utility. Int J Clin Oncol 2017;22:421-30.

35. Leroy S, Benzaquen J, Mazzetta A, Marchand-Adam S, Padovani $B$, Israel-Biet D, et al. Circulating tumour cells as a potential screening tool for lung cancer (the AIR study): protocol of a prospective multicentre cohort study in France. BMJ Open 2017;7: e018884.

36. Cabel L, Proudhon C, Mariani P, Tzanis D, Beinse G, Bieche I, et al. Circulating tumor cells and circulating tumor DNA: what surgical oncologists need to know? Eur J Surg Oncol 2017;43:949-62.

37. Cristofanilli M, Hayes DF, Budd GT, Ellis MJ, Stopeck A, Reuben JM, et al. Circulating tumor cells: a novel prognostic factor for newly diagnosed metastatic breast cancer. J Clin Oncol 2005;23: 1420-30.

38. Cohen SJ, Punt CJ, lannotti N, Saidman BH, Sabbath KD, Gabrail NY, et al. Relationship of circulating tumor cells to tumor response, progression-free survival, and overall survival in patients with metastatic colorectal cancer. J Clin Oncol 2008;26: 3213-21.

39. de Bono JS, Scher HI, Montgomery RB, Parker C, Miller MC, Tissing $\mathrm{H}$, et al. Circulating tumor cells predict survival benefit from treatment in metastatic castration-resistant prostate cancer. Clin Canc Res 2008;14:6302-9.

40. Schochter F, FriedI TWP, deGregorio A, Krause S, Huober J, Rack B, et al. Are circulating tumor cells (CTCs) ready for clinical use in breast cancer? An overview of completed and ongoing trials using CTCs for clinical treatment decisions. Cells 2019;8:1412.

41. Jacot W, Cottu P, Berger F, Dubot C, Venat-Bouvet L, Lortholary A, et al. Actionability of HER2-amplified circulating tumor cells in HER2-negative metastatic breast cancer: the CirCe T-DM1 trial. Breast Cancer Res 2019;21:121.

42. Armstrong AJ, Halabi S, Luo J, Nanus DM, Giannakakou P, Szmulewitz RZ, et al. Prospective multicenter validation of androgen receptor splice variant 7 and hormone therapy resistance in high-risk castration-resistant prostate cancer: the PROPHECY study. J Clin Oncol 2019;37:1120-9.

43. Keller L, Pantel K. Unravelling tumour heterogeneity by single-cell profiling of circulating tumour cells. Nat Rev Canc 2019;19: 553-67.

44. Valihrach L, Androvic P, Kubista M. Platforms for single-cell collection and analysis. Int J Mol Sci 2018;19:807.

45. Lim SB, Lim CT, Lim WT. Single-cell analysis of circulating tumor cells: why heterogeneity matters. Cancers 2019;11:1595.

46. Lim SB, Di Lee W, Vasudevan J, Lim WT, Lim CT. Liquid biopsy: one cell at a time. NPJ Precis Oncol 2019;3:23.

47. Salvianti F, Pazzagli M, Pinzani P. Single circulating tumor cell sequencing as an advanced tool in cancer management. Expert Rev Mol Diagn 2016;16:51-63. 
48. Salvianti F, Pinzani P. The diagnostic potential of mutation detection from single circulating tumor cells in cancer patients. Expert Rev Mol Diagn 2017;17:975-81.

49. Aoki M, Shoji H, Kashiro A, Takeuchi K, Shimizu Y, Honda K. Prospects for comprehensive analyses of circulating tumor cells in tumor biology. Cancers 2020;12:1135.

50. Salvianti F, Gelmini S, Costanza F, Mancini I, Sonnati G, Simi L, et al. The pre-analytical phase of the liquid biopsy. N Biotechnol 2020;55:19-29.

51. Aucamp J, Bronkhorst AJ, Badenhorst CPS, Pretorius PJ. The diverse origins of circulating cell-free DNA in the human body: a critical re-evaluation of the literature. Biol Rev Camb Phil Soc 2018;93:1649-83.

52. Bettegowda C, Sausen M, Leary RJ, Kinde I, Wang Y, Agrawal N, et al. Detection of circulating tumor DNA in early- and late-stage human malignancies. Sci Transl Med 2014;6:224ra24.

53. Siravegna G, Marsoni S, Siena S, Bardelli A. Integrating liquid biopsies into the management of cancer. Nat Rev Clin Oncol 2017; 14:531-48.

54. Vymetalkova V, Cervena K, Bartu L, Vodicka P. Circulating cellfree DNA and colorectal cancer: a systematic review. Int J Mol Sci 2018;19:3356.

55. Wan JCM, Massie C, Garcia-Corbacho J, Mouliere F, Brenton JD, Caldas $C$, et al. Liquid biopsies come of age: towards implementation of circulating tumour DNA. Nat Rev Canc 2017;17: 223-38.

56. Fleischhacker M, Schmidt B. Circulating nucleic acids (CNAs) and cancer-a survey. Biochim Biophys Acta Rev Canc 2007;1775: 181-232.

57. Cheng F, Su L, Qian C. Circulating tumor DNA: a promising biomarker in the liquid biopsy of cancer. Oncotarget 2016;7: 48832-41.

58. García-Olmo DC, Domínguez C, García-Arranz M, Anker P, Stroun M, García-Verdugo J, et al. Cell-free nucleic acids circulating in the plasma of colorectal cancer patients induce the oncogenic transformation of susceptible cultured cells. Canc Res 2010;70: 560-7.

59. Elazezy M, Joosse SA. Techniques of using circulating tumor DNA as a liquid biopsy component in cancer management. Comput Struct Biotechnol J 2018;16:370-8.

60. Diehl F, Schmidt K, Choti MA, Romans K, Goodman S, Li M, et al. Circulating mutant DNA to assess tumor dynamics. Nat Med 2008;14:985-90.

61. Diehl F, Li M, Dressman D, He Y, Shen D, Szabo S, et al. Detection and quantification of mutations in the plasma of patients with colorectal tumors. Proc Natl Acad Sci USA 2005;102:16368-73.

62. De Rubis G, Rajeev Krishnan S, Bebawy M. Liquid biopsies in cancer diagnosis, monitoring, and prognosis. Trends Pharmacol Sci 2019;40:172-86.

63. Tzimagiorgis G, Michailidou EZ, Kritis A, Markopoulos AK, Kouidou S. Recovering circulating extracellular or cell-free RNA from bodily fluids. Cancer Epidemiol 2011;35:580-9.

64. Escors D, Gato-Cañas M, Zuazo M, Arasanz H, García-Granda MJ, Vera R, et al. The intracellular signalosome of PD-L1 in cancer cells. Signal Transduct Target Ther 2018;3:26.

65. Ishiba T, Ho_mann AC, Usher J, Elshimali Y, Sturdevant T, Dang M, et al. Frequencies and expression levels of programmed death ligand 1 (PD-L1) in circulating tumor RNA (ctRNA) in various cancer types. Biochem Biophys Res Commun 2018;500:621-5.
66. Junqueira-Neto S, Batista IA, Costa JL, Melo SA. Liquid biopsy beyond circulating tumor cells and cell-free DNA. Acta Cytol 2019; 63:479-88.

67. Otsuji K, Sasaki T, Tanaka A, Kunita A, Ikemura M, Matsusaka K, et al. Use of droplet digital PCR for quantitative and automatic analysis of the HER2 status in breast cancer patients. Breast Canc Res Treat 2017;162:11-8.

68. Leong SP, Ballesteros-Merino C, Jensen SM, Marwitz S, Bifulco C Fox BA, et al. Novel frontiers in detecting cancer metastasis. Clin Exp Metastasis 2018;35:403-12.

69. Zhao X, Cai Y, Xu J. Circular RNAs: biogenesis, mechanism, and function in human cancers. Int J Mol Sci 2019;20:3926.

70. Kalluri R. The biology and function of exosomes in cancer. J Clin Invest 2016;126:1208-15.

71. Thakur BK, Zhang H, Becker A, Matei I, Huang Y, Costa-Silva, et al. Double-stranded DNA in exosomes: a novel biomarker in cancer detection. Cell Res 2014;24:766-9.

72. Kahlert C, Kalluri R. Exosomes in tumor microenvironment influence cancer progression and metastasis. J Mol Med (Berl) 2013;91:431-7.

73. Jia Y, Chen Y, Wang Q, Jayasinghe U, Luo X, Wei Q, et al. Exosome: emerging biomarker in breast cancer. Oncotarget 2017;8: 41717-33.

74. Gori A, Romanato A, Greta B, Strada A, Gagni P, Frigerio R, et al. Membrane-binding peptides for extracellular vesicles on-chip analysis. J Extracell Vesicles 2020;9:1751428.

75. Taylor DD, Gercel-Taylor C. MicroRNA signatures of tumor-derived exosomes as diagnostic biomarkers of ovarian cancer. Gynecol Oncol 2008;110:13-21.

76. Skog J, Wurdinger T, van Rijn S, Meijer DH, Gainche L, SenaEsteves M, et al. Glioblastoma microvesicles transport RNA and proteins that promote tumour growth and provide diagnostic biomarkers. Nat Cell Biol 2008;10:1470-6.

77. Mellinghoff IK, Wang MY, Vivanco I, Haas-Kogan DA, Zhu S, Dia $E Q$, et al. Molecular determinants of the response of glioblastomas to EGFR kinase inhibitors. N Engl J Med 2005;353: 2012-24.

78. Peinado H, Alečković M, Lavotshkin S, Matei I, Costa-Silva B, Moreno-Bueno G, et al. Melanoma exosomes educate bone marrow progenitor cells toward a pro-metastatic phenotype through MET. Nat Med 2012;18:883-91.

79. Silva J, Garcia V, Rodriguez M, Compte M, Cisneros E, Veguillas P, et al. Analysis of exosome release and its prognostic value in human colorectal cancer. Genes Chromosomes Cancer 2012;51: 409-18.

80. Gaballa R, Ali HEA, Mahmoud MO, Rhim JS, Ali HI, Salem HF, et al. Exosomes-mediated transfer of Itga2 promotes migration and invasion of prostate cancer cells by inducing epithelialmesenchymal transition. Cancers 2020;12:2300.

81. Del Re M, Crucitta S, Sbrana A, Rofi E, Paolieri F, Gianfilippo G, et al. AR-V7 and AR-FL expression is associated with clinical outcome: a translational study in patients with castrate resistant prostate cancer. BJU Int 2019. https://doi.org/10.1111/bju.14792.

82. Hoshino A, Costa-Silva B, Shen TL, Rodrigues G, Hashimoto A, Tesic Mark M, et al. Tumour exosome integrins determine organotropic metastasis. Nature 2015;527:329-35.

83. DeSantis CE, Ma J, Goding Sauer A, Newman LA, Jemal A. Breast cancer statistics, 2017, racial disparity in mortality by state. Ca Cancer J Clin 2017;67:439-48. 
84. Siegel RL, Miller KD, Jemal A. Cancer statistics, 2018. Ca - Cancer J Clin 2018;68:7-30.

85. Buono G, Gerratana L, Bulfoni M, Provinciali N, Basile D, Giuliano $M$, et al. Circulating tumor DNA analysis in breast cancer: is it ready for prime-time? Canc Treat Rev 2019;73:73-83.

86. Cayrefourcq L, Alix-Panabières C. Clinical relevance of liquid biopsy in breast cancer: update in 2020. Expert Rev Mol Diagn 2020;20:913-9.

87. Lucci A, Hall CS, Lodhi AK, Bhattacharyya A, Anderson AE, Xiao L, et al. Circulating tumour cells in non-metastatic breast cancer: a prospective study. Lancet Oncol 2012;13:688-95.

88. Rack B, Schindlbeck C, Juckstock J, Andergassen U, Hepp P, Zwingers T, et al. Circulating tumor cells predict survival in early average-to-high risk breast cancer patients. J Natl Cancer Inst 2014;106:dju066.

89. Bidard FC, Michiels S, Riethdorf S, Mueller V, Esserman LJ, Lucci A, et al. Circulating tumor cells in breast cancer patients treated by neoadjuvant chemotherapy: a meta-analysis. J Natl Cancer Inst 2018;110:560-7.

90. Trapp E, Janni W, Schindlbeck C, Jückstock J, Andergassen U, de Gregorio A, et al. Presence of circulating tumor cells in highrisk early breast cancer during follow-up and prognosis. J Natl Cancer Inst 2019;111:380-7.

91. Cristofanilli M, Budd GT, Ellis MJ, Stopeck A, Matera J, Miller MC, et al. Circulating tumor cells, disease progression, and survival in metastatic breast cancer. N Engl J Med 2004;351:781-91.

92. Budd GT, Cristofanilli M, Ellis MJ, Stopeck A, Borden E, Miller MC, et al. Circulating tumor cells versus imaging-predicting overall survival in metastatic breast cancer. Clin Canc Res 2006;12: 6403-9.

93. Bidard FC, Peeters DJ, Fehm T, Nolé F, Gisbert-Criado R, Mavroudis D, et al. Clinical validity of circulating tumour cells in patients with metastatic breast cancer: a pooled analysis of individual patient data. Lancet Oncol 2014;15:406-14.

94. Liu MC, Shields PG, Warren RD, Cohen P, Wilkinson M, Ottaviano YL, et al. Circulating tumor cells: a useful predictor of treatment efficacy in metastatic breast cancer. J Clin Oncol 2009;27:5153-9.

95. Smerage JB, Barlow WE, Hortobagyi GN, Winer EP, Leyland-Jones $B$, Srkalovic G, et al. Circulating tumor cells and response to chemotherapy in metastatic breast cancer: SWOG S0500. J Clin Oncol 2014;32:3483-9.

96. Bidard F-C, Jacot W, Dureau S, Brain E, Bachelot T, Bourgeois H, et al. Abstract GS3-07: clinical utility of circulating tumor cell count as a tool to choose between first line hormone therapy and chemotherapy for ER+ HER2- metastatic breast cancer: results of the phase III STIC CTC trial. Canc Res 2019;79(4 Suppl):GS3-07-GS3-07.

97. Cristofanilli M, Pierga JY, Reuben J, Rademaker A, Davis AA, Peeters DJ, et al. The clinical use of circulating tumor cells (CTCS) enumeration for staging of metastatic breast cancer (MBC): international expert consensus paper. Crit Rev Oncol Hematol 2019;134:39-45.

98. Babayan A, Hannemann J, Spotter J, Müller V, Pantel K, Joosse SA. Heterogeneity of estrogen receptor expression in circulating tumor cells from metastatic breast cancer patients. PloS One 2013;8:e75038.

99. Krause S, Friedl T, Romashova T, Fasching PA, Schneeweiss A, Müller V, et al. Abstract OT1-10-01: DETECT III/IV study trial - the multicenter study program in patients with HER2-negative metastatic breast cancer and circulating tumor cells. Canc Res 2019;79(4 Suppl):0T1-10-01-0T1-10-01.
100. Jacot W, Mazel M, Mollevi C, Pouderoux S, D’Hondt V, Cayrefourcq $\mathrm{L}$, et al. Clinical correlations of programmed cell death ligand 1 status in liquid and standard biopsies in breast cancer. Clin Chem 2020;66:1093-101.

101. Koch C, Kuske A, Joosse S, Yigit G, Sflomos G, Thaler S, et al. Characterization of circulating breast cancer cells with tumorigenic and metastatic capacity. EMBO Mol Med 2020: e11908.

102. Malani R, Fleisher M, Kumthekar P, Lin X, Omuro A, Groves MD, et al. Cerebrospinal fluid circulating tumor cells as a quantifiable measurement of leptomeningeal metastases in patients with HER2 positive cancer. J Neuro Oncol 2020;148: 599-606.

103. Pantel K, Alix-Panabieres C. Liquid biopsy and minimal residual disease - latest advances and implications for cure. Nat Rev Clin Oncol 2019;16:409-24.

104. Ma F, Zhu W, Guan Y, Yang L, Xia X, Chen S, et al. ctDNA dynamics: a novel indicator to track resistance in metastatic breast cancer treated with anti-HER2 therapy. Oncotarget 2016; 7:66020-31.

105. Sakai H, Tsurutani J, Iwasa T, Komoike Y, Sakai K, Nishio K, et al. HER2 genomic amplification in circulating tumor DNA and estrogen receptor positivity predict primary resistance to trastuzumab emtansine (T-DM1) in patients with HER2-positive metastatic breast cancer. Breast Cancer 2018; 25:605-13.

106. Fribbens C, Garcia Murillas I, Beaney M, Hrebien S, O'Leary B, Kilburn L, et al. Tracking evolution of aromatase inhibitor resistance with circulating tumour DNA analysis in metastatic breast cancer. Ann Oncol 2018;29:145-53.

107. Andrè F, Ciruelos EM, Juric D, Loibl S, Campone M, Mayer I, et al. LBA18 Overall survival (os) results from SOLAR-1, a phase III study of alpelisib (ALP) + fulvestrant (FUL) for hormone receptorpositive $(\mathrm{HR}+)$, human epidermal growth factor receptor 2-negative (HER2-) advanced breast cancer (ABC). Ann Oncol 2020:S1150-1. https://doi.org/10.1016/j.annonc.2020.08. 2246.

108. Del Re M, Crucitta S, Lorenzini G, De Angelis C, Diodati L, Cavallero D, et al. PI3K mutations detected in liquid biopsy are associated to reduced sensitivity to CDK4/6 inhibitors in metastatic breast cancer patients. Pharmacol Res 2020:105241. https://doi.org/10.1016/j.phrs.2020.105241.

109. O’Leary B, Cutts RJ, Huang X, Hrebien S, Liu Y, André F, et al. Circulating tumor DNA markers for early progression on fulvestrant with or without palbociclib in ER+ advanced breast cancer. JNCI J Natl Cancer Inst 2021;113:djaa087.

110. O'Leary B, Hrebien S, Morden JP, Beaney M, Fribbens C, Huang X, et al. Early circulating tumor DNA dynamics and clonal selection with palbociclib and fulvestrant for breast cancer. Nat Commun 2018;9:896.

111. Del Re M, Bertolini I, Crucitta S, Fontanelli L, Rofi E, De Angelis C, et al. Overexpression of TK1 and CDK9 in plasma-derived exosomes is associated with clinical resistance to CDK4/6 inhibitors in metastatic breast cancer patients. Breast Canc Res Treat 2019;178:57-62.

112. Shaw JA, Guttery DS, Hills A, Fernandez-Garcia D, Page K, Rosales BM, et al. Mutation analysis of cell-free DNA and single circulating tumor cells in metastatic breast cancer patients with high circulating tumor cell counts. Clin Canc Res 2017;23: 88-96. 
113. Davis AA, Zhang Q, Gerratana L, Shah AN, Zhan Y, Qiang W, et al. Association of a novel circulating tumor DNA next-generating sequencing platform with circulating tumor cells (CTCS) and CTC clusters in metastatic breast cancer. Breast Cancer Res 2019;21: 137.

114. Keup C, Benyaa K, Hauch S, Sprenger-Haussels M, Tewes M, Mach $\mathrm{P}$, et al. Targeted deep sequencing revealed variants in cell-free DNA of hormone receptor-positive metastatic breast cancer patients. Cell Mol Life Sci 2020;77:497-509.

115. Gerratana L, Zhang Q, Shah AN, Davis AA, Zhang Y, Wehbe F, et al. Performance of a novel Next Generation Sequencing circulating tumor DNA (ctDNA) platform for the evaluation of samples from patients with metastatic breast cancer (MBC). Crit Rev Oncol Hematol 2020;145:102856.

116. Kolenčík D, Shishido SN, Pitule P, Mason J, Hicks J, Kuhn P. Liquid biopsy in colorectal carcinoma: clinical applications and challenges. Cancers 2020;12:1376.

117. Ding Y, Li W, Wang K, Xu C, Hao M, Ding L. Perspectives of the application of liquid biopsy in colorectal cancer. BioMed Res Int 2020;2020:6843180.

118. Danese E, Montagnana M, Lippi G. Circulating molecular biomarkers for screening or early diagnosis of colorectal cancer: which is ready for prime time? Ann Transl Med 2019;7:610.

119. Marcuello M, Vymetalkova V, Neves RPL, Duran-Sanchon S, Vedeld HM, Tham E, et al. Circulating biomarkers for early detection and clinical management of colorectal cancer. Mol Aspect Med 2019;69:107-22.

120. Eliasova P, Pinkas M, Kolostova K, Gurlich R, Bobek V. Circulating tumor cells in different stages of colorectal cancer. Folia Histochem Cytobiol 2017;55:1-5.

121. Zhao R, Cai Z, Li S, Cheng Y, Gao H, Liu F, et al. Expression and clinical relevance of epithelial and mesenchymal markers in circulating tumor cells from colorectal cancer. Oncotarget 2017; 8:9293-302.

122. Gerdtsson AS, Thiele JA, Shishido SN, Zheng S, Schaffer R, Bethel K, et al. Single cell correlation analysis of liquid and solid biopsies in metastatic colorectal cancer. Oncotarget 2019;10: 7016-30.

123. Mostert B, Jiang Y, Sieuwerts AM, Wang H, Bolt-de Vries J, Biermann $\mathrm{K}$, et al. KRAS and BRAF mutation status in circulating colorectal tumor cells and their correlation with primary and metastatic tumor tissue. Int J Canc 2013;133:130-41.

124. Buim ME, Fanelli MF, Souza VS, Romero J, Abdallah EA, Mello CA, et al. Detection of KRAS mutations in circulating tumor cells from patients with metastatic colorectal cancer. Canc Biol Ther 2015; 16:1289-95.

125. Mohamed Suhaimi NA, Foong YM, Lee DY, Phyo WM, Cima I, Lee EX, et al. Non-invasive sensitive detection of KRAS and BRAF mutation in circulating tumor cells of colorectal cancer patients. Mol Oncol 2015;9:850-60.

126. Sastre J, Orden V, Martínez A, Bando I, Balbín M, Bellosillo B, et al. Association between baseline circulating tumor cells, molecular tumor profiling, and clinical characteristics in a large cohort of chemo-naïve metastatic colorectal cancer patients prospectively collected. Clin Colorectal Canc 2020;S1533-0028: 30037-2.

127. Yang C, Zou K, Zheng L, Xiong B. Prognostic and clinicopathological significance of circulating tumor cells detected by RT-PCR in non-metastatic colorectal cancer: a metaanalysis and systematic review. BMC Canc 2017;17:725.
128. Tan $\mathrm{Y}, \mathrm{Wu} \mathrm{H}$. The significant prognostic value of circulating tumor cells in colorectal cancer: a systematic review and metaanalysis. Curr Probl Canc 2018;42:95-106.

129. Molnar B, Ladanyi A, Tanko L, Sréter L, Tulassay Z. Circulating tumor cell clusters in the peripheral blood of colorectal cancer patients. Clin Canc Res 2001;7:4080-5.

130. Chen JY, Tsai WS, Shao HJ, Wu JC, Lai JM, Lu SH, et al. Sensitive and specific biomimetic lipid coated microfluidics to isolate viable circulating tumor cells and microemboli for cancer detection. PloS One 2016;11:e0149633.

131. Lankiewicz S, Zimmermann S, Hollmann C, Hillemann T, Greten TF. Circulating tumour cells as a predictive factor for response to systemic chemotherapy in patients with advanced colorectal cancer. Mol Oncol 2008;2:349-55.

132. Neki K, Kawahara H, Watanabe K, Toyama Y, Akiba T, Yanaga K. Usefulness of circulating tumor cells after preliminary chemotherapy for prediction of response to further anticancer therapy in patients with initially unresectable metastatic colorectal cancer. Anticancer Res 2013;33:1769-72.

133. Kalikaki A, Politaki H, Souglakos J, Apostolaki S, Papadimitraki E, Georgoulia N, et al. KRAS genotypic changes of circulating tumor cells during treatment of patients with metastatic colorectal cancer. PloS One 2014;9:e104902.

134. Lu CY, Uen YH, Tsai HL, Chuang SC, Hou MF, Wu DC, et al. Molecular detection of persistent postoperative circulating tumour cells in stages II and III colon cancer patients via multiple blood sampling: prognostic significance of detection for early relapse. $\mathrm{Br} J$ Canc 2011;104:1178-84.

135. Ma B, King AD, Leung L, Wang K, Poon A, Ho WM, et al. Identifying an early indicator of drug efficacy in patients with metastatic colorectal cancer-a prospective evaluation of circulating tumor cells, 18F-fluorodeoxyglucose positronemission tomography and the RECIST criteria. Ann Oncol 2017; 28:1576-81.

136. Arrazubi V, Mata E, Antelo ML, Tarifa A, Herrera J, Zazpe C, et al. Circulating tumor cells in patients undergoing resection of colorectal cancer liver metastases. Clinical utility for long-term outcome: a prospective trial. Ann Surg Oncol 2019;26:2805-11.

137. Fabbri F, Carloni S, Zoli W, Ulivi P, Gallerani G, Fici P, et al. Detection and recovery of circulating colon cancer cells using a dielectrophoresis-based device: KRAS mutation status in pure CTCs. Canc Lett 2013;335:225-31.

138. Kondo Y, Hayashi K, Kawakami K, Miwa Y, Hayashi H, Yamamoto M. KRAS mutation analysis of single circulating tumor cells from patients with metastatic colorectal cancer. BMC Canc 2017;17: 311.

139. Heitzer E, Auer M, Gasch C, Pichler M, Ulz P, Hoffmann EM, et al. Complex tumor genomes inferred from single circulating tumor cells by array-CGH and next-generation sequencing. Canc Res 2013;73:2965-75.

140. Abouleila Y, Onidani K, Ali A, Shoji H, Kawai T, Lim CT, et al. Live single cell mass spectrometry reveals cancer-specific metabolic profiles of circulating tumor cells. Canc Sci 2019;110:697-706.

141. Burz C, Rosca A, Pop VV, Buiga R, Aldea C, Samasca G, et al. Liquid biopsy challenge and hope in colorectal cancer. Expert Rev Mol Diagn 2019;19:341-8.

142. Germano G, Mauri G, Siravegna G, Dive C, Pierce J, Di Nicolantonio F, et al. Parallel evaluation of circulating tumor DNA and circulating tumor cells in metastatic colorectal cancer. Clin Colorectal Canc 2018;17:80-3. 
143. Kloten V, Ruchel N, Bruchle NO, Gasthaus J, Freudenmacher N, Steib F, et al. Liquid biopsy in colon cancer: comparison of different circulating DNA extraction systems following absolute quantification of KRAS mutations using Intplex allele-specific PCR. Oncotarget 2017;8:86253-63.

144. Cassinotti E, Melson J, Liggett T, Melnikov A, Yi Q, Replogle C, et al. DNA methylation patterns in blood of patients with colorectal cancer and adenomatous colorectal polyps. Int I Canc 2012;131:1153-7.

145. Ahlquist T, Lind GE, Costa VL, Meling GI, Vatn M, Hoff GS, et al. Gene methylation profiles of normal mucosa, and benign and malignant colorectal tumors identify early onset markers. Mol Canc 2008;7:94.

146. Danese E, Montagnana M. Epigenetics of colorectal cancer: emerging circulating diagnostic and prognostic biomarkers. Ann Transl Med 2017;5:279.

147. Hanley MP, Hahn MA, Li AX, Wu X, Lin J, Wang J, et al. Genomewide DNA methylation profiling reveals cancer-associated changes within early colonic neoplasia. Oncogene 2017;36: 5035-44.

148. Lam K, Pan K, Linnekamp JF, Medema JP, Kandimalla R. DNA methylation based biomarkers in colorectal cancer: a systematic review. Biochim Biophys Acta 2016;1866:106-20.

149. Petit J, Carroll G, Gould T, Pockney P, Dun M, Scott RJ. Cell-free DNA as a diagnostic blood-based biomarker for colorectal cancer: a systematic review. J Surg Res 2019;236:184-97.

150. Song L, Li Y. SEPT9: a specific circulating biomarker for colorectal cancer. Adv Clin Chem 2015;72:171-204.

151. Sun G, Meng J, Duan H, Zhang D, Tang Y. Diagnostic assessment of septin9 DNA methylation for colorectal cancer using blood detection: a meta-analysis. Pathol Oncol Res 2019;25:1525-34.

152. Nian J, Sun X, Ming SY, Yan C, Ma Y, Feng Y, et al. Diagnostic accuracy of methylated SEPT9 for blood-based colorectal cancer detection: a systematic review and meta-analysis. Clin Transl Gastroenterol 2017;8:e216.

153. Lin JK, Lin PC, Lin CH, Jiang JK, Yang SH, Liang WY, et al. Clinical relevance of alterations in quantity and quality of plasma DNA in colorectal cancer patients: based on the mutation spectra detected in primary tumors. Ann Surg Oncol 2014;21(4 Suppl): S680-6.

154. Yang YC, Wang D, Jin L, Yao HW, Zhang JH, Wang J, et al. Circulating tumor DNA detectable in early- and late-stage colorectal cancer patients. Biosci Rep 2018;38:BSR20180322.

155. Cohen JD, Li L, Wang Y, Thoburn C, Afsari B, Danilova L, et al. Detection and localization of surgically resectable cancers with a multi-analyte blood test. Science 2018;359:926-30.

156. Merker JD, Oxnard GR, Compton C, Diehn M, Hurley P, Lazar AJ, et al. Circulating tumor DNA analysis in patients with cancer: American Society of Clinical Oncology and College of American Pathologists joint review. J Clin Oncol 2018;36:1631-41.

157. Demuth C, Spindler KG, Johansen JS, Pallisgaard N, Nielsen D, Hogdall E, et al. Measuring KRAS mutations in circulating tumor DNA by droplet digital PCR and next-generation sequencing. Transl Oncol 2018;11:1220-4.

158. Siravegna G, Mussolin B, Buscarino M, Corti G, Cassingena A, Crisafulli G, et al. Clonal evolution and resistance to EGFR blockade in the blood of colorectal cancer patients. Nat Med 2015;21:827.

159. Cremolini C, Rossini D, Dell'Aquila E, Lonardi S, Conca E, Del Re $M$, et al. Rechallenge for patients with RAS and BRAF wild-type metastatic colorectal cancer with acquired resistance to firstline cetuximab and irinotecan: a phase 2 single-arm clinical trial. JAMA Oncol 2019;5:343-50.

160. Reinert T, Scholer LV, Thomsen R, Tobiasen H, Vang S, Nordentoft I, et al. Analysis of circulating tumour DNA to monitor disease burden following colorectal cancer surgery. Gut 2016; 65:625-34.

161. Dagogo-Jack I, Shaw AT. Tumour heterogeneity and resistance to cancer therapies. Nat Rev Clin Oncol 2018;15:81-94.

162. Hu Z, Li Z, Ma Z, Curtis C. Multi-cancer analysis of clonality and the timing of systemic spread in paired primary tumors and metastases. Nat Genet 2020;52:701-8.

163. Neumann MHD, Bender S, Krahn T, Schlange T. ctDNA and CTCs in liquid biopsy - current status and where we need to progress. Comput Struct Biotechnol J 2018;16:190-5.

164. Cui S, Cheng Z, Qin W, Jiang L. Exosomes as a liquid biopsy for lung cancer. Lung Canc 2018;116:46-54.

165. Liu L, Lin F, Ma X, Chen Z, Yu J. Tumor-educated platelet as liquid biopsy in lung cancer patients. Crit Rev Oncol Hematol 2020; 146:102863.

166. Lu S, Kong H, Hou Y, Ge D, Huang W, Ou J, et al. Two plasma microRNA panels for diagnosis and subtype discrimination of lung cancer. Lung Canc 2018;123:44-51.

167. Canale M, Pasini L, Bronte G, Delmonte A, Cravero P, Crinò L, et al. Role of liquid biopsy in oncogene-addicted non-small cell lung cancer. Transl Lung Cancer Res 2019;8(3 Suppl):S265-79.

168. Revelo AE, Martin A, Velasquez R, Kulandaisamy PC, Bustamante J, Keshishyan S, et al. Liquid biopsy for lung cancers: an update on recent developments. Ann Transl Med 2019;7:349.

169. Rolfo C, Mack PC, Scagliotti GV, Baas P, Barlesi F, Bivona TG, et al. Liquid biopsy for advanced non-small cell lung cancer (NSCLC): a statement paper from the IASLC. J Thorac Oncol 2018; 13:1248-68.

170. Jamal-Hanjani M, Wilson GA, McGranahan N, Birkbak NJ, Watkins TBK, Veeriah S, et al. Tracking the evolution of nonsmall-cell lung cancer. N Engl J Med 2017;376:2109-21.

171. Leon SA, Shapiro B, Sklaroff DM, Yaros MJ. Free DNA in the serum of cancer patients and the effect of therapy. Canc Res 1977;37:646-50.

172. Szpechcinski A, Rudzinski P, Kupis W, Langfort R, Orlowski T, Chorostowska-Wynimko J. Plasma cell-free DNA levels and integrity in patients with chest radiological findings: NSCLC versus benign lung nodules. Canc Lett 2016;374:202-7.

173. Soliman SE, Alhanafy AM, Habib MSE, Hagag M, Ibrahem RAL. Serum circulating cell free DNA as potential diagnostic and prognostic biomarker in non small cell lung cancer. Biochem Biophys Rep 2018;15:45-51.

174. Kuang Y, Rogers A, Yeap BY, Wang L, Makrigiorgos M, Vetrand K, et al. Noninvasive detection of EGFR T790M in gefitinib or erlotinib resistant non-small cell lung cancer. Clin Canc Res 2009;15:2630-36.

175. Sundaresan TK, Sequist LV, Heymach JV, Riely GJ, Jänne PA, Koch WH. Detection of T790M, the acquired resistance EGFR mutation, by tumor biopsy versus noninvasive blood-based analyses. Clin Canc Res 2016;22:1103-10.

176. Oxnard GR, Thress KS, Alden RS, Lawrance R, Paweletz CP, Cantarini $M$, et al. Association between plasma genotyping and outcomes of treatment with osimertinib (AZD9291) in advanced non-small-cell lung cancer. J Clin Oncol 2016;34:3375-82. 
177. Oxnard GR. The cellular origins of drug resistance in cancer. Nat Med 2016;22:232-4.

178. Cortot AB, Jänne PA. Molecular mechanisms of resistance in epidermal growth factor receptor-mutant lung adenocarcinomas. Eur Respir Rev 2014;23:356-66.

179. Murtaza M, Dawson S, Tsui DWY, Gale D, Forshew T, Piskorz AM, et al. Non-invasive analysis of acquired resistance to cancer therapy by sequencing of plasma DNA. Nature 2013;497: 108-12.

180. Suda K, Murakami I, Sakai K, Mizuuchi H, Shimizu S, Sato K, et al. Small cell lung cancer transformation and T790M mutation: complimentary roles in acquired resistance to kinase inhibitors in lung cancer. Sci Rep 2015;5:14447.

181. Izumi H, Yamasaki A, Ueda Y, Sumikawa T, Maeta $\mathrm{H}$, Nakamoto S, et al. Squamous cell carcinoma transformation from EGFR-mutated lung adenocarcinoma: a case report and literature review. Clin Lung Canc 2018;1: e63-6.

182. Zhang Z, Yang S, Wang Q. Impact of MET alterations on targeted therapy with EGFR-tyrosine kinase inhibitors for EGFR-mutant lung cancer. Biomark Res 2019;7:27.

183. Herter-Sprie GS, Greulich H, Wong KK. Activating mutations in ERBB2 and their impact on diagnostics and treatment. Front Oncol 2013;3:86.

184. Eng J, Woo KM, Sima CS, Plodkowski A, Hellmann MD, Chaft JE, et al. Impact of concurrent PIK3CA mutations on response to EGFR tyrosine kinase inhibition in EGFR-mutant lung cancers and on prognosis in oncogene-driven lung adenocarcinomas. J Thorac Oncol Off Publ Int Assoc Study Lung Canc 2015;10: 1713-9.

185. Xu J, Wang J, Zhang S. Mechanisms of resistance to irreversible epidermal growth factor receptor tyrosine kinase inhibitors and therapeutic strategies in non-small cell lung cancer. Oncotarget 2017;8:90557-78.

186. Thress KS, Paweletz CP, Felip E, Cho BC, Stetson D, Dougherty B, et al. Acquired EGFR C797S mutation mediates resistance to AZD9291 in non-small cell lung cancer harboring EGFR T790M. Nat Med 2015;21:560-2.

187. Cui S, Zhang W, Xiong L, Pan F, Niu Y, Chu T, et al. Use of capturebased next-generation sequencing to detect ALK fusion in plasma cell-free DNA of patients with non-small-cell lung cancer. Oncotarget 2017;8:2771-80.

188. Dagogo-Jack I, Brannon AR, Ferris LA, Campbell CD, Lin JJ, Schultz KR, et al. Tracking the evolution of resistance to ALK tyrosine kinase inhibitors through longitudinal analysis of circulating tumor DNA. JCO Precis Oncol 2018;2018: P0.17.00160.

189. Bordi P, Tiseo M, Rofi E, Petrini I, Restante G, Danesi R, et al. Detection of ALK and KRAS mutations in circulating tumor DNA of patients with advanced ALK-positive NSCLC with disease progression during crizotinib treatment. Clin Lung Canc 2017; 18:692-7.

190. McCoach CE, Blakely CM, Banks KC, Levy B, Chue BM, Raymond VM, et al. Clinical utility of cell-free DNA for the detection of ALK fusions and genomic mechanisms of ALK inhibitor resistance in non-small cell lung cancer. Clin Canc Res 2018;24:2758-70.

191. Camidge DR, Doebele RC, Kerr KM. Comparing and contrasting predictive biomarkers for immunotherapy and targeted therapy of NSCLC. Nat Rev Clin Oncol 2019;16:341-55.
192. Garon EB, Rizvi NA, Hui R, Leighl N, Balmanoukian AS, Eder JP, et al. Pembrolizumab for the treatment of non-small-cell lung cancer. N Engl J Med 2015;372:2018-28.

193. Herbst RS, Baas P, Kim DW, Felip E, Pérez-Gracia JL, Han JY, et al. Pembrolizumab versus docetaxel for previously treated, PD-L1-positive, advanced non-small-cell lung cancer (KEYNOTE-010): a randomised controlled trial. Lancet 2016;387: 1540-50.

194. Antonia SJ, Villegas A, Daniel D, Vicente D, Murakami S, Hui R, et al. Overall survival with durvalumab after chemoradiotherapy in stage III NSCLC. N Engl J Med 2018;379:2342-50.

195. Antonia SJ, Villegas A, Daniel D, Vicente D, Murakami S, Hui R, et al. Durvalumab after chemoradiotherapy in stage III nonsmall-cell lung cancer. N Engl J Med 2017;377:1919-29.

196. Ilie M, Long-Mira E, Bence C, Butori C, Lassalle S, Bouhlel L, et al. Comparative study of the PD-L1 status between surgically resected specimens and matched biopsies of NSCLC patients reveal major discordances: a potential issue for anti-PD-L1 therapeutic strategies. Ann Oncol 2016;27:147-53.

197. Liu Y, Dong Z, Jiang T, Hou L, Wu F, Gao G, et al. Heterogeneity of PD-L1 expression among the different histological components and metastatic lymph nodes in patients with resected lung adenosquamous carcinoma. Clin Lung Canc 2018;19:e421-30.

198. Ilié M, Szafer-Glusman E, Hofman V, Chamorey E, Lalvée S, Selva $\mathrm{E}$, et al. Detection of PD-L1 in circulating tumor cells and white blood cells from patients with advanced non-small-cell lung cancer. Ann Oncol 2018;29:193-9.

199. Vona G, Sabile A, Louha M, Sitruk V, Romana S, Schütze K, et al. Isolation by size of epithelial tumor cells : a new method for the immunomorphological and molecular characterization of circulating tumor cells. Am J Pathol 2000;156:57-63.

200. Adams DL, Stefansson S, Haudenschild C, Martin SS, Charpentier M, Chumsri S, et al. Cytometric characterization of circulating tumor cells captured by microfiltration and their correlation to the CellSearch(囚) CTC test. Cytometry 2015;87: 137-44.

201. Miller MC, Robinson PS, Wagner C, O’Shannessy DJ. The ParsortixTM cell separation system-a versatile liquid biopsy platform. Cytometry 2018;93:1234-9.

202. Sollier E, Go DE, Che J, Gossett DR, O'Byrne S, Weaver WM, et al. Size-selective collection of circulating tumor cells using Vortex technology. Lab Chip 2014;14:63-77.

203. Lee Y, Guan G, Bhagat AA. ClearCell $\circledast$ FX, a label-free microfluidics technology for enrichment of viable circulating tumor cells. Cytometry 2018;93:1251-4.

204. Riethdorf S, Fritsche H, Müller V, Rau T, Schindlbeck C, Rack B, et al. Detection of circulating tumor cells in peripheral blood of patients with metastatic breast cancer: a validation study of the CellSearch system. Clin Canc Res 2007;13:920-8.

205. Werner SL, Graf RP, Landers M, Valenta DT, Schroeder M, Greene $\mathrm{SB}$, et al. Analytical validation and capabilities of the epic CTC platform: enrichment-free circulating tumour cell detection and characterization. J Circ Biomarkers 2015;4:3.

206. Theil G, Fischer K, Weber E, Medek R, Hoda R, Lücke K, et al. The use of a new cell collector to isolate circulating tumor cells from the blood of patients with different stages of prostate cancer and clinical outcomes - a proof-of-concept study. PloS One 2016;11:e0158354.

207. Asgarova A, Asgarov K, Godet Y, Peixoto P, Nadaradjane A, Boyer-Guittaut $\mathrm{M}$, et al. PD-L1 expression is regulated by both 
DNA methylation and NF-kB during EMT signaling in non-small cell lung carcinoma. Oncolmmunology 2018;7:e1423170.

208. Qu QX, Huang Q, Shen Y, Zhu YB, Zhang XG. The increase of circulating PD-L1-expressing CD68(+) macrophage in ovarian cancer. Tumour Biol J Int Soc Oncodevelopmental Biol Med 2016;37:5031-7.

209. Schehr JL, Schultz ZD, Warrick JW, Guckenberger DJ, Pezzi HM, Sperger JM, et al. High specificity in circulating tumor cell identification is required for accurate evaluation of programmed death-ligand 1. PloS One 2016;11:e0159397.

210. Kim DH, Kim H, Choi YJ, Kim SY, Lee JE, Sung KJ, et al. Exosomal PD-L1 promotes tumor growth through immune escape in nonsmall cell lung cancer. Exp Mol Med 2019;51:1-13.

211. Rizvi NA, Hellmann MD, Snyder A, Kvistborg P, Makarov V, Havel JJ, et al. Cancer immunology. Mutational landscape determines sensitivity to PD-1 blockade in non-small cell lung cancer. Science 2015;348:124-8.

212. Galuppini F, Dal Pozzo CA, Deckert J, Loupakis F, Fassan M, Baffa R. Tumor mutation burden: from comprehensive mutational screening to the clinic. Canc Cell Int 2019;19:209.

213. Rizvi H, Sanchez-Vega F, La K, Chatila W, Jonsson P, Halpenny D, et al. Molecular determinants of response to anti-programmed cell death (PD)-1 and anti-programmed death-ligand 1 (PD-L1) blockade in patients with non-small-cell lung cancer profiled with targeted next-generation sequencing. I Clin Oncol 2018;36: 633-41.

214. Lo JA, Fisher DE. The melanoma revolution: from UV carcinogenesis to a new era in therapeutics. Science 2014;346:945-9.

215. Finn L, Markovic SN, Joseph RW. Therapy for metastatic melanoma: the past, present, and future. BMC Med 2012;10:23.

216. Pellegrini C, Cardelli L, Padova M, Nardo LD, Ciciarelli V, Rocco T, et al. Intra-patient heterogeneity of BRAF and NRAS molecular alterations in primary melanoma and metastases. Acta Derm Venereol 2020;100:adv00040.

217. Shain AH, Bastian BC. From melanocytes to melanomas. Nat Rev Canc 2016;16:345-58.

218. Lee CS, Thomas CM, Ng KE. An overview of the changing landscape of treatment for advanced melanoma. Pharmacotherapy 2017;37:319-33.

219. Vanni I, Tanda ET, Spagnolo F, Andreotti V, Bruno W, Ghiorzo P. The current state of molecular testing in the BRAF-mutated melanoma landscape. Front Mol Biosci 2020;7:113.

220. Gaiser MR, von Bubnoff N, Gebhardt C, Utikal JS. Liquid biopsy to monitor melanoma patients. JDDG J der Deutschen Dermatol Gesellschaft 2018;16:405-14.

221. Boyer M, Cayrefourcq L, Dereure O, Meunier L, Becquart O, AlixPanabières $\mathrm{C}$. Clinical relevance of liquid biopsy in melanoma and Merkel cell carcinoma. Cancers 2020;12:960.

222. Marsavela G, Aya-Bonilla CA, Warkiani ME, Gray ES, Ziman M. Melanoma circulating tumor cells: benefits and challenges required for clinical application. Canc Lett 2018;424:1-8.

223. Tucci M, D’Oronzo S, Mannavola F, Felici C, Lovero D, Cafforio P, et al. Dual-procedural separation of CTCs in cutaneous melanoma provides useful information for both molecular diagnosis and prognosis.Ther Adv Med Oncol 2020;12: 1758835920905415

224. Klinac D, Gray ES, Freeman JB, Reid A, Bowyer S, Millward M, et al. Monitoring changes in circulating tumour cells as a prognostic indicator of overall survival and treatment response in patients with metastatic melanoma. BMC Canc 2014;14:423.

225. Khattak MA, Reid A, Freeman J, Pereira M, McEvoy A, Lo J, et al. PD-L1 expression on circulating tumor cells may be predictive of response to pembrolizumab in advanced melanoma: results from a pilot study. Oncol 2020;25:e520-7.

226. Gorges K, Wiltfang L, Gorges TM, Sartori A, Hildebrandt L, Keller $\mathrm{L}$, et al. Intra-patient heterogeneity of circulating tumor cells and circulating tumor DNA in blood of melanoma patients. Cancers 2019;11:1685.

227. Fusi A, Collette S, Busse A, Suciu S, Rietz A, Santinami M, et al. Circulating melanoma cells and distant metastasis-free survival in stage III treatment (EORTC 18991 side study). Eur J Canc 2009; 45:3189-97.

228. Busser B, Lupo J, Sancey L, Mouret S, Faure P, Plumas J, et al. Plasma circulating tumor DNA levels for the monitoring of melanoma patients: landscape of available technologies and clinical applications. BioMed Res Int 2017;2017:5986129.

229. Gray ES, Rizos H, Reid AL, Pereira MR, Lo J, Tembe V, et al. Circulating tumor DNA to monitor treatment response and detect acquired resistance in patients with metastatic melanoma. Oncotarget 2015;6:42008-18.

230. Forschner A, Battke F, Hadaschik D, Schulze M, Weissgraeber S, Han CT, et al. Tumor mutation burden and circulating tumor DNA in combined CTLA-4 and PD-1 antibody therapy in metastatic melanoma-results of a prospective biomarker study. J Immunother Canc 2019;7:180.

231. Seremet T, Jansen Y, Planken S, Njimi H, Delaunoy M, El Housni $\mathrm{H}$, et al. Undetectable circulating tumor DNA (ctDNA) levels correlate with favorable outcome in metastatic melanoma patients treated with anti-PD1 therapy. J Transl Med 2019;17: 303.

232. Mori T, O’Day SJ, Umetani N, Martinez SR, Kitago M, Koyanagi K, et al. Predictive utility of circulating methylated DNA in serum of melanoma patients receiving biochemotherapy. J Clin Oncol 2005;23:9351-8.

233. Koyanagi K, Mori T, O’Day SJ, Martinez SR, Wang HJ, Hoon DSB, et al. Association of circulating tumor cells with serum tumorrelated methylated DNA in peripheral blood of melanoma patients. Canc Res 2006;66:6111-7.

234. Lo Nigro C, Wang H, McHugh A, Lattanzio L, Matin R, Harwood C, et al. Methylated tissue factor pathway inhibitor 2 (TFPI2) DNA in serum is a biomarker of metastatic melanoma. J Invest Dermatol 2013;133:1278-85.

235. Váraljai R, Elouali S, Lueong SS, Wistuba-Hamprecht K, Seremet T, Siveke JT, et al. The predictive and prognostic significance of cell-free DNA concentration in melanoma. J Eur Acad Dermatol Venereol 2020. https://doi.org/10.1111/jdv. 16766.

236. Polini B, Carpi S, Romanini A, Breschi MC, Nieri P, Podestà A. Circulating cell-free microRNAs in cutaneous melanoma staging and recurrence or survival prognosis. Pigment Cell Melanoma Res 2019;32:486-99.

237. Del Re M, Marconcini R, Pasquini G, Rofi E, Vivaldi C, Bloise F, et al. PD-L1 mRNA expression in plasma-derived exosomes is associated with response to anti-PD- 1 antibodies in melanoma and NSCLC. Br J Cancer 2018;118:820-4. 